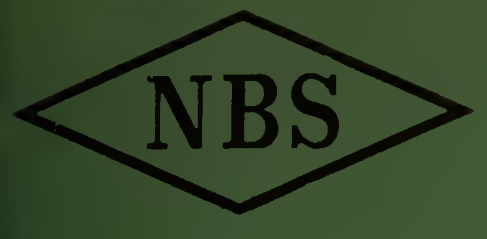

Eechnical Note

no. 138

\title{
Boulder Laboratories
}

\section{VERTICAL CROSS SECTIONS OF THE IONOSPHERE ACROSS \\ THE GEOMAGNETIC EQUATOR}

\author{
BY J. W. WRIGHT
}

U. S. DEPARTMENT OF COMMERCE NATIONAL BUREAU OF STANDARDS 


\section{THE NATIONAL BUREAU OF STANDARDS}

\section{Functions and Activities}

The functions of the National Bureau of Standards are set forth in the Act of Congress, March 3, 1901, 3s amended by Congress in Public Law 619, 1950. These include the development and maintenance of the national standards of measurement and the provision of means and methods for making measurements consistent with these standards; the determination of physical constants and properties of materials; the development of methods and instruments for testing materials, devices, and structures; advisory services to government agencies on scientific and technical problems; invention and development of devices to serve special needs of the Government; and the development of standard practices, codes, and specifications. The work includes basic and applied research, development, engineering, instrumentation, testing, evaluation, calibration services, and various consultation and information services. Research projects are also performed for other government agencies when the work relates to and supplements the basic program of the Bureau or when the Bureau's unique competence is required. The scope of activities is suggested by the listing of divisions and sections on the inside of the back cover.

\section{Publications}

The results of the Bureau's research are published either in the Bureau's own series of publications or in the journals of professional and scientific societies. The Bureau itself publishes three periodicals available from the Government Printing Office: The Journal of Research, published in four separate sections, presents complete scientific and technical papers; the Technical News Bulletin presents summary and preliminary reports on work in progress; and Basic Radio Propagation Predictions provides data for determining the best frequencies to use for radio conmunications throughout the world. There are also five series of nonperiodical puhlications: Honographs, Applied Mathematics Series, Handbooks, Miscellaneous Publications, and Technical Notes.

A complete listing of the Bureau's publications can be found in National Bureau of Standards Circular 460, Publications of the National Bureau of Standards, 1901 to June 1947 (\$1.25), and the Supplement to National Bureau of Standards Circular 460, July 1947 to June 1957 ( $\$ 1.50)$, and Miscellaneous Publication 240, July 1957 to June 1960 (Includes Titles of Papers Published in Outside Journals 1950 to 1959) (\$2.25); available from the Superintendent of Documents, Government Printing Office, Washington 25, D. C. 


\section{NATIONAL BUREAU OF STANDARDS Eechnical Mote}

\section{8}

April 6, 1962

\section{Vertical Cross Sections of the Ionosphere Across the Geomagnetic Equator}

by

J. W. Wright

National Bureau of Standards

Boulder, Colorado

NBS Technical Notes are designed to supplement the Bureau's regular publications program. They provide a means for making available scientific data that are of transient or limited interest. Technical Notes may be listed or referred to in the open literature. They are for sale by the Office of Technical Services, U. S. Department of Commerce, Washington 25, D. C.

\section{DISTRIBUTED BY \\ UNITED STATES DEPARTMENT OF COMMERCE OFFICE OF TECHNICAL SERVICES \\ WASHINGTON 25, D. C.}

Price $\$ 1.00$ 



\title{
Vertical Cross Sections of the Ionosphere Across the Geomagnetic Equator*
}

\author{
J. W. Wright \\ National Bureau of Standards \\ Boulder, Colorado
}

\begin{abstract}
Contours of ionization along a meridian crossing the geomagnetic equator are shown for each hour of a quiet period in March 1958. The equatorial ionospheric anomalies are thereby illustrated and discussed phenomenologically. The probable physical processes are described.
\end{abstract}

* A study carried out under Contract Number NTF-84 with the National Aeronautics and Space Administration.

This Technical Note is also available in a Spanish version upon request. 

Vertical Cross Sections of the Ionosphere

Across the Geomagnetic Equator

\author{
J. W. Wright \\ National Bureau of Standards \\ Boulder, Colorado
}

\title{
I. Introduction
}

Probably the largest and most consistent horizontal gradients of electron density in the ionosphere are those in the vicinity of the geomagnetic equator. Although evident in world maps of the F2 layer critical frequency (foF 2), and therefore recognized for many years, it has become possible to visualize the detailed structure of these anomalies only since the development of methods for obtaining electron density profiles from the basic ionospheric sounding data. The operation during the IGY of a relatively close-spaced chain of sounding stations along the $75^{\circ} \mathrm{W}$ meridian and across the geomagnetic equator, was another essential requirement for the adequate description of this remarkable part of the ionosphere.

The National Aeronautics and Space Administration has supported at the National Bureau of Standards, a substantial program concerned with the determination of height profiles of electron density using ionospheric vertical soundings, with a special view toward the provision of ionospheric data essential to various scientific and practical aspects of space programs. As a pilot study, the NBS has undertaken an intensive analysis of ionograms from the chain of stations located along the $75^{\circ} \mathrm{W}$ meridian from Washington, D. C. to Concepcion, Chile. Because a chain of Minitrack satellite tracking stations also extends roughly along the $75^{\circ} \mathrm{W}$ meridian, it was considered to be of especial interest to examine closely the detailed structure and anomalies of the ionosphere in this region. The resulting graphical representations should be particularly useful for agencies concerned with satellite radio 
measurements in the vicinity of the geomagnetic equator. These data permit a precise evaluation of satellite-tracking refraction errors by ray tracing techniques. But it is perhaps in their graphic illustration of unique phenomena to the ionospheric scientist and observer, that such cross sections find their greatest interest. For this report, we have selected a sequence showing the diurnal variation of the quiet equatorial ionosphere during a period of high solar activity in the equinox. It is in these circumstances that the anomalies are most dramatically evident.

\section{Construction of the Cross Sections}

Hourly electron density profiles were computed for eleven moderate and low latitude stations, for ten equinoctial days, near the peak of the solar cycle (March $22-31,1958)$. Hourly averages of the electron density at each $10 \mathrm{~km}$ level were then obtained over the ten day period. The eleven stations are as follows:

\begin{tabular}{lrlcc} 
Station & Latitude & Longitude & $\begin{array}{c}\text { Magnetic } \\
\text { Dip }\end{array}$ & $\begin{array}{c}\text { Geomagnetic } \\
\text { Latitude }\end{array}$ \\
\hline Fort Belvoir & $38^{\circ} 44^{\prime} \mathrm{N}$ & $77^{\circ} 08^{\prime} \mathrm{W}$ & $71.9^{\circ} \mathrm{N}$ & $50.1^{\circ} \mathrm{N}$ \\
Grand Bahama Island & $26^{\circ} 40^{\prime} \mathrm{N}$ & $78^{\circ} 22^{\prime}$ & $59.5^{\circ} \mathrm{N}$ & $37.9^{\circ} \mathrm{N}$ \\
Puerto Rico & $18^{\circ} 30^{\prime} \mathrm{N}$ & $67^{\circ} 12$ & $51.5^{\circ} \mathrm{N}$ & $30.0^{\circ} \mathrm{N}$ \\
Panama, Canal Zone & $9^{\circ} 23^{\prime} \mathrm{N}$ & $79^{\circ} 53^{\prime}$ & $37^{\circ} \mathrm{N}$ & $20.6^{\circ} \mathrm{N}$ \\
Bogota, Colombia & $4^{\circ} 32^{\prime} \mathrm{N}$ & $74^{\circ} 15^{\prime}$ & $32^{\circ} \mathrm{N}$ & $15.9^{\circ} \mathrm{N}$ \\
Talara, Peru & $4^{\circ} 34^{\prime} \mathrm{S}$ & $81^{\circ} 15^{\prime}$ & $13^{\circ} \mathrm{N}$ & $6.6^{\circ} \mathrm{N}$ \\
Chiclayo, Peru & $6^{\circ} 48^{\prime} \mathrm{S}$ & $79^{\circ} 49^{\prime}$ & $10^{\circ} \mathrm{N}$ & $4.4^{\circ} \mathrm{N}$ \\
Chimbote, Peru & $9^{\circ} 04^{\prime} \mathrm{S}$ & $78^{\circ} 35^{\prime}$ & $7^{\circ} \mathrm{N}$ & $2.2^{\circ} \mathrm{N}$ \\
Huancayo, Peru & $12^{\circ} 03^{\prime} \mathrm{S}$ & $75^{\circ} 20^{\prime}$ & $0.5^{\circ} \mathrm{N}$ & $0.6^{\circ} \mathrm{S}$ \\
La Paz, Bolivia & $16^{\circ} 29^{\prime} \mathrm{S}$ & $68^{\circ} 03^{\prime}$ & $5^{\circ} \mathrm{S}$ & $5.0^{\circ} \mathrm{S}$ \\
Concepcion, Chile & $36^{\circ} 35^{\prime} \mathrm{S}$ & $72^{\circ} 59^{\prime}$ & $36^{\circ} \mathrm{S}$ & $25.3^{\circ} \mathrm{S}$ \\
\hline
\end{tabular}


The average electron density profiles permit determination of the actual heights of reflection of (vertically incident) radio waves in the ionosphere. Radio frequency thus becomes a convenient parameter, and contours of equal "plasma frequency" (in $\mathrm{Mc} / \mathrm{s}$ ) have been drawn in the height-latitude plane, one graph for each hour. For physical clarity, our discussions will be in terms of the electron density, related directly to the plasma frequency by the relation $\mathrm{N}\left(\right.$ electrons $\left./ \mathrm{cm}^{3}\right)=12,400 \mathrm{fN}_{\mathrm{N}}^{2}(\mathrm{Mc} / \mathrm{s})$.

The electron density reaches a peak value, typically at altitudes of $300-500 \mathrm{~km}$. This height of maximum is represented on the graphs by a heavy dashed line. It is important to note that the vertical soundings give no information about the electron density profile at altitudes above this peak. In an effort to present a more complete picture of the vertical and horizontal structure of the trans-equatorial ionosphere, the observations have therefore been extrapolated above the peak according to a standard model. It has been shown (Wright 1960) that the model agrees well with available data on the "topside" F-region; from the work of Hirono (1955) it follows that the model has considerable theoretical justification except at the magnetic equator. Additional work by Lyon (unpublished) indicates a similar model at the geomagnetic equator, at least asympotically; very recent observations with the incoherent scatter method by Bowles near Lima, Peru also tend to confirm the use of this model near the geomagnetic equator.

The model used for these vertical cross sections may be written $N=N m \exp \frac{1}{2}\left(1-z-e^{-z}\right)$, where $z$ is a normalized height coordinate measured above the layer peak in units of the (ionizable constituent) scale height, H. For sunspot maximum conditions it was shown (Wright, 1960) that $\mathrm{H}=100 \mathrm{~km}$ gave reasonable agreement with avail able rocket and satellite information; this value has accordingly been used in the present work. 
Light dashed lines show the geomagnetic (dipole) field at each $5^{\mathrm{C}}$ of geomagnetic latitude. Finally, it must be noted that the vertical scale is expanded to eleven times that of the horizontal scale.

\section{Description of the Phenomena}

This section will describe the main feature s of the equatorial ionosphere as they are portrayed on the following diagrams. In the final section, a brief qualitative explanation of this behavior will be attempted.

Perhaps the first and most striking phenomenon to be noted is the very great height of the $F$-region peak in the immediate vicinity of the geomagnetic equator from mid-morning (0900 hours LMT) to late evening (2000). This is a regular occurrence at all seasons, altitudes of $600 \mathrm{~km}$ or more for the $F$-region peak being not uncommon. To a less spectacular degree, this phenomenon is reversed in the late evening and night hours (2200 - 0500), the F-region then being lower over the equator than elsewhere. It is interesting to note the accelerated rise of the F-region in the early evening, after the disappearance of the E-region (1900) followed by an equally rapid fall after (2100). The asymmetry of the phenomena with respect to the geomagnetic equator appears to be real. It is enhanced, not removed, if the true (surface) magnetic field is used instead of the geomagnetic dipole field since the geomagnetic equator is north of the dip equator in these longitudes.

The second remarkable equatorial phenomenon is the very high electron densities found at geomagnetic latitudes of about $\pm 15^{\circ}$, at local times between 1200 - 0400. There is good evidence from critical frequency data for the existence of such peaks of electron density both north and south of the equator. Along the $75^{\circ} \mathrm{W}$ meridian, unfortunately, no data at the rather critical southern position was available for this study. Thus, the apparent asymmetry in electron density near $-15^{\circ}$ geomagnetic latitude may be partly spurious. It must be noted, however, that an electron density asymmetry is confirmed at geomagnetic latitudes of $\pm 8^{\circ}$ and $\pm 25^{\circ}$. 
Within the narrow zone at $\pm 15^{\circ}$ geomagnetic latitude are found the highest ionospheric electron densities ever observed. (During February 1956, near the recent maximum of the sunspot cycle, a peak electron density of nearly $6 \times 10^{6} \mathrm{el} / \mathrm{cm}^{3}$ (plasma frequency $=24 \mathrm{Mc} / \mathrm{s}$ ) was observed at Okinawa, a similar location).

The diurnal variations of the electron density in this narrow region, are of great interest: choosing 0500 as a convenient starting place because of the absence of any apparent anomalies at this time throughout the transequatorial region, we note that the first significant occurrence of an enhanced electron density at $+15^{\circ}$ occurs about 1200 . It increases at first slowly, and then very rapidly reaching its diurnal maximum value at about 2000 . It may be remembered that it is also at this time that the equatorial $F$-region begins to descend rapidly. The enhanced ionization at $+15^{\circ}$ then decreases slowly throughout the evening, a peak still being noticeable until 0300.

\section{Discussion}

The anomalies in these illustrations are obviously related to the geomagnetic field, showing at least approximate symmetry about the geomagnetic equator. It is, of course, in this narrow region that the geomagnetic field has no vertical component. In two rather separate ways, this horizontal geomagnetic field profoundly affects the distribution of ionization in the equatorial ionosphere:

a. The horizontal magnetic field is associated with the generation of particularly strong vertical electrodynamic drift forces.

b. The horizontal magnetic field inhibits the otherwise rapid vertical diffusion of the ionization. 
The "dynamo theory" of the observed quiet-day geomagnetic variations (the Sq variation) shows that horizontal (tidal) air currents in the E-region of the ionosphere give rise to an east-west electrostatic field, which -- acting with the horizontal (north-south) magnetic field -- results in a vertical drift force on the charged particles in the F-region.

This drift force has a strong sinusoidal diurnal variation, being maximum (upwards) shortly before noon, and directed downwards at night. The following sequence of events therefore appears to be responsible for the variations observed in the accompanying illustrations; again selecting 0500 as a convenient starting point:

1. 0500 - 0800: The most significant influence at these times of day is the great increase in electron production in the $E$ and F regions following sunrise. Electron production is first noticeable in the upper F region (0600) as sunlight strikes it at grazing incidence. By 0700 the lower F-region and E-region are "filled in" by this process, which gives a rapid increase in electron density throughout the $100-500 \mathrm{~km}$ region until $1000-1100$.

2. $0900-1700$ : As a result of sunrise production of ionization, the conductivity in the E-region increases by a factor of over 10; together with the concurrent solar tidal motions of ionization in the E-region, this gives rise to an upward drift force on the ionization of the F-region. At higher latitudes, the effects of this drift force would be largely overcome by downward diffusion of the charged particles, and the F-region would remain at a considerably lower altitude. But over the equator, the horizontal magnetic field inhibits vertical diffusion; the F-region therefore becomes greatly distended in the vertical direction. Also important is the fact that, at the great altitudes attained by the ionization, electron loss processes are quite slow. Thus, the ionization is carried to regions at great heights from which it cannot easily escape, and in which it can be preserved for relatively long periods. The total content of ionization over the equator during the daytime therefore becomes very large. 
However, the ionization at great altitudes over the equator is not entirely hindered from reaching lower heights. As first suggested by Mitra (1946), the ionization can diffuse along the magnetic field in the direction of the magnetic meridian, under gravity and its own pressure gradient and thereby arrive at the points north and south of the equator where the lines of force terminate. The ionization confined between field lines $500-1000 \mathrm{~km}$ above the geomagnetic equator, converges on rather narrow regions between $15^{\circ}$ and $25^{\circ}$ north and south magnetic latitude. This diffusion along the field under the influence of gravity and pressure gradients, probably is responsible for the high electron densities found at geomagnetic latitudes near $\pm 20^{\circ}$. Duncan (1961) has examined this process quantitatively, and finds it adequate to explain these concentrations of ionization. We propose the term "Equatorial Fountain" as a concise term for these processes.

3. 1700 - 2000: Electrons disappear in the lower ionosphere through the rapid loss processes occurring there; this becomes noticeable with sunset and the cessation of electron production. There is still a considerable upward vertical displacement of the F-region ionization, which reaches its greatest integrated effect between 1900 and 2000 , although the drift force is beginning, at these hours, to be directed downward.

4. 2000 - 0500: The downward motion of the F-region into a region previously left vacant by the combined processes of upward drift, electron loss, and diminishing electron production, is very striking. In the course of a few hours the F-region peak is brought from altitudes of about $600 \mathrm{~km}$, down to $300-400 \mathrm{~km}$. The lower boundary is probably determined by the very rapid increase of los $\mathrm{s}$ rate with decreasing height, electrons disappearing by loss as rapidly as they are brought to this level. But the forces by which the ionization can descend so rapidly, are not yet clear. A current system capable of producing a nighttime downward electrodynamic drift comparable to that known to exist in the daytime, would appear to require 
greater E region conductivity than can be expected from the electron densities of the nighttime E region. However, other processes are perhaps acting in a similar direction. For example, the cooling and consequent subsidence of the $F$ region in the evening is perhaps responsible for some of the observed downward movement.

Considering that the loss rate increases exponentially downwards, it is an impressive measure of the effect of the downward drift - - whatever its cause -- that the nighttime equatorial F-region is found some 30-60 km lower than at moderate latitudes, where a constant re-supply of electrons is necessary to maintain the observed densities.

Quite probably the subsidence of the neutral atmosphere also assists the meridional diffusion of ionization to higher latitudes (dis cussed in (2) above), resulting in the great increase of electron density near geomagnetic latitudes of $\pm 20^{\circ}$ in the late evening.

\section{Acknowledgements}

I wish to express my appreciation for many helpful and illuminating discussions with my colleagues R. A. Duncan (CSIRO, Camden, Australia), and S. Radicella (University of Tucuman).

\section{References}

R. A. Duncan, "The equatorial F-region of the ionosphere", J. Atmos. Terrest. Phys., 18, 89-99 (1959).

M. Hirono, "Effect of gravity and pressure gradient on vertical drift in the F2 region", Rept. on Iono. Res. in Japan 9 No. 2, 95-104 (1955).

S. N. Mitra, "Geomagnetic control of region F2 of the ionosphere", Nature 158, 668-669 (1946).

J. W. Wright, "A model of the F region above hmaxF2", J. of Geophysical Research, 65, 185 (1960). 


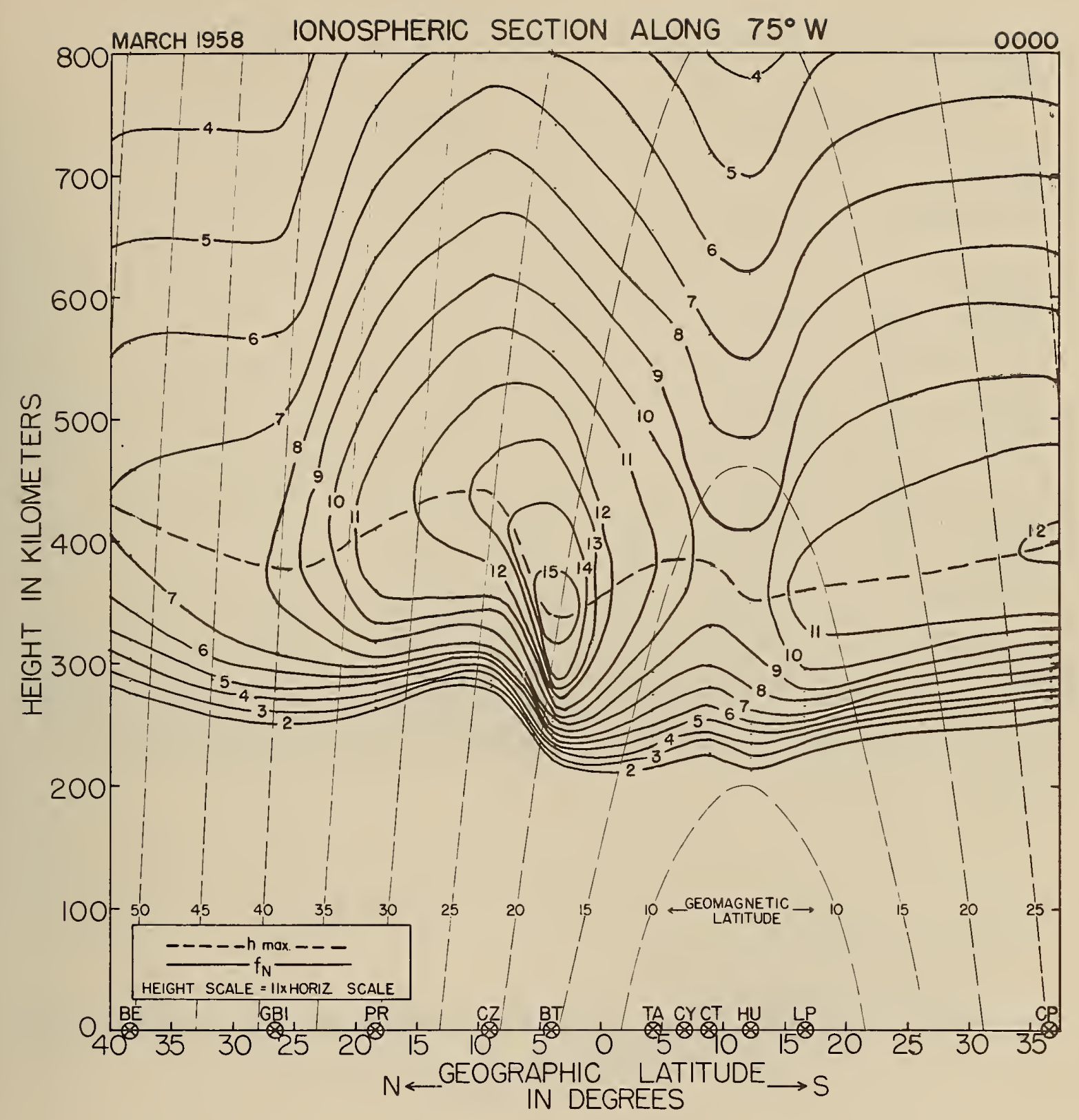




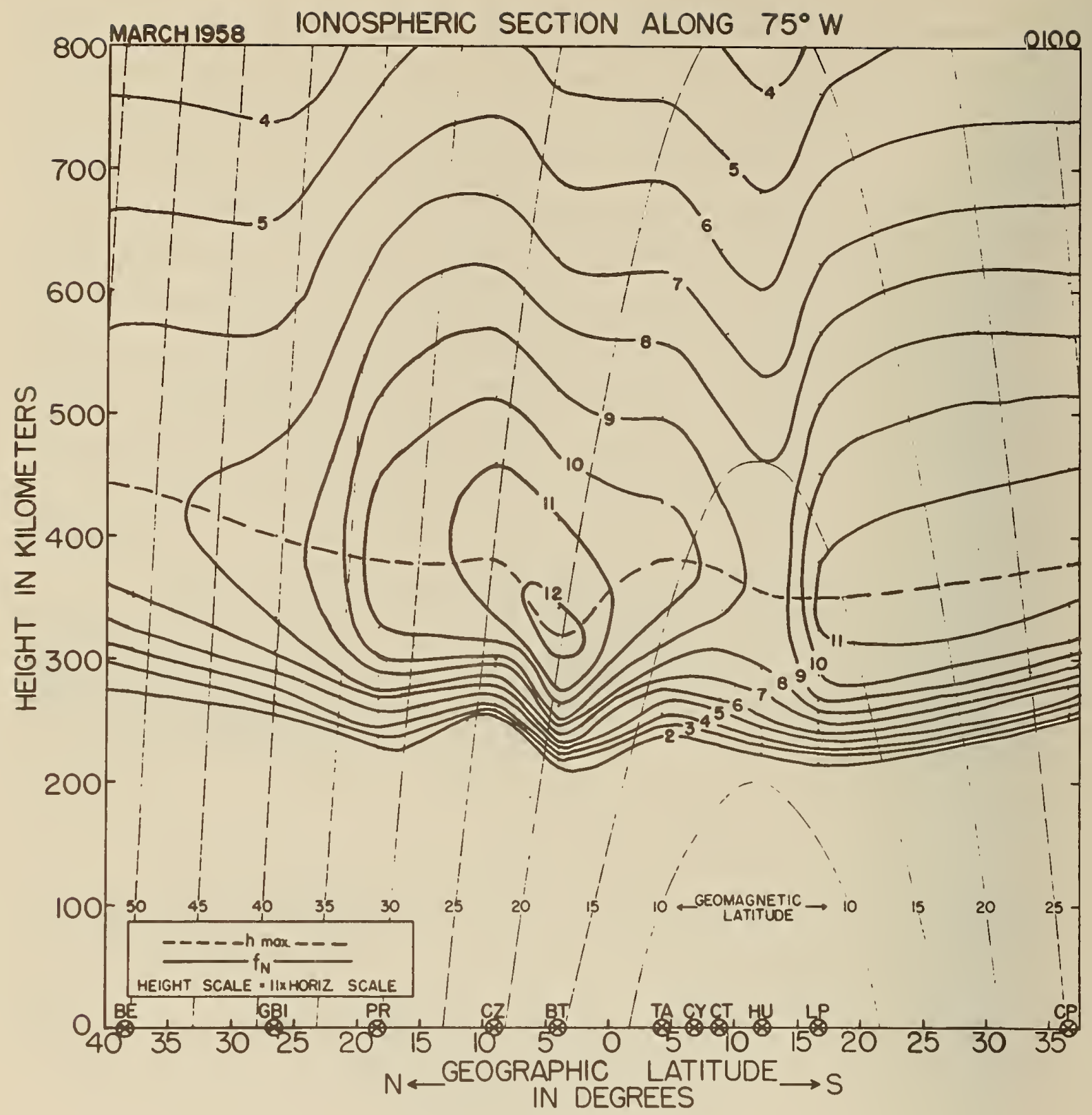




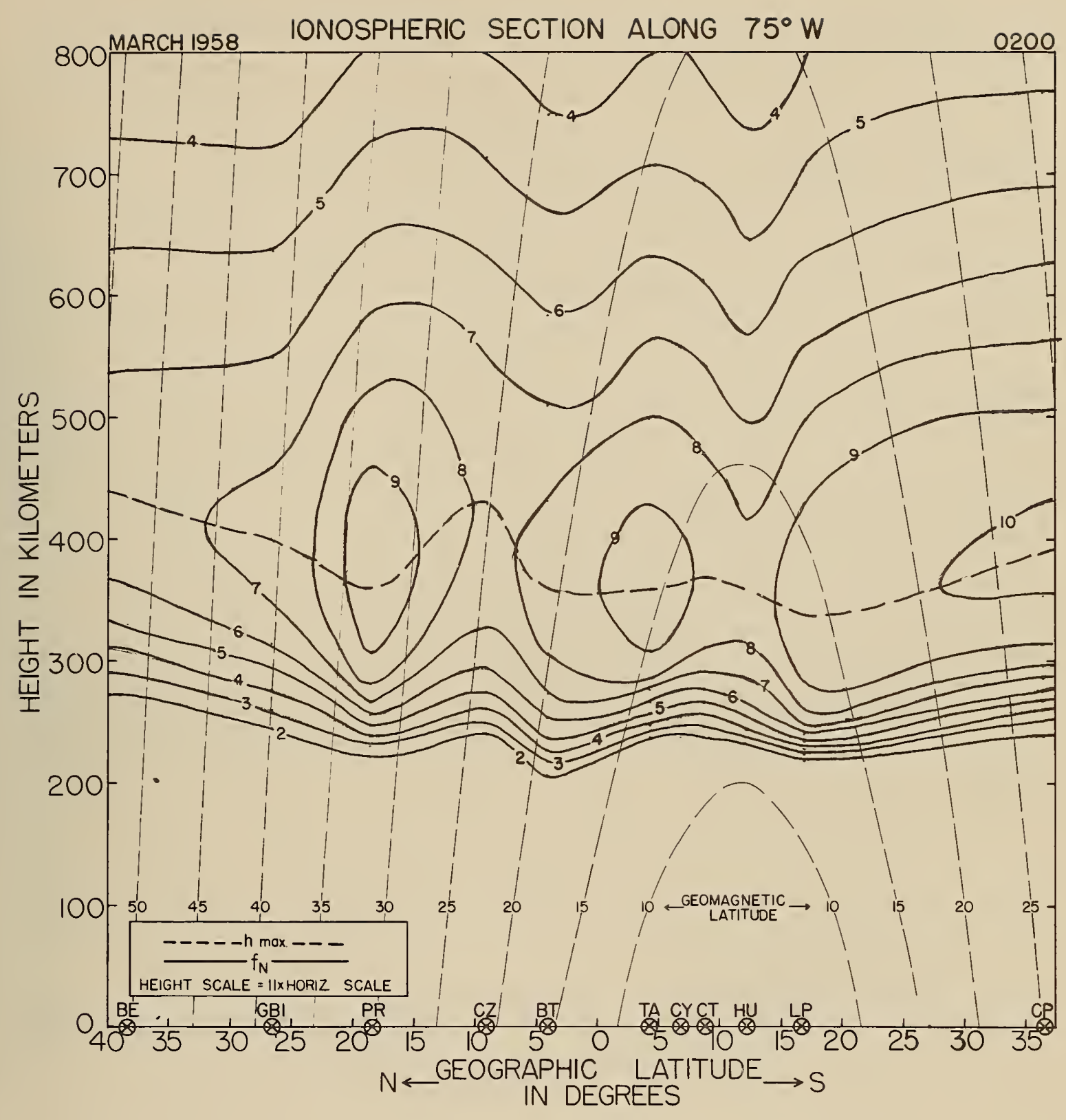




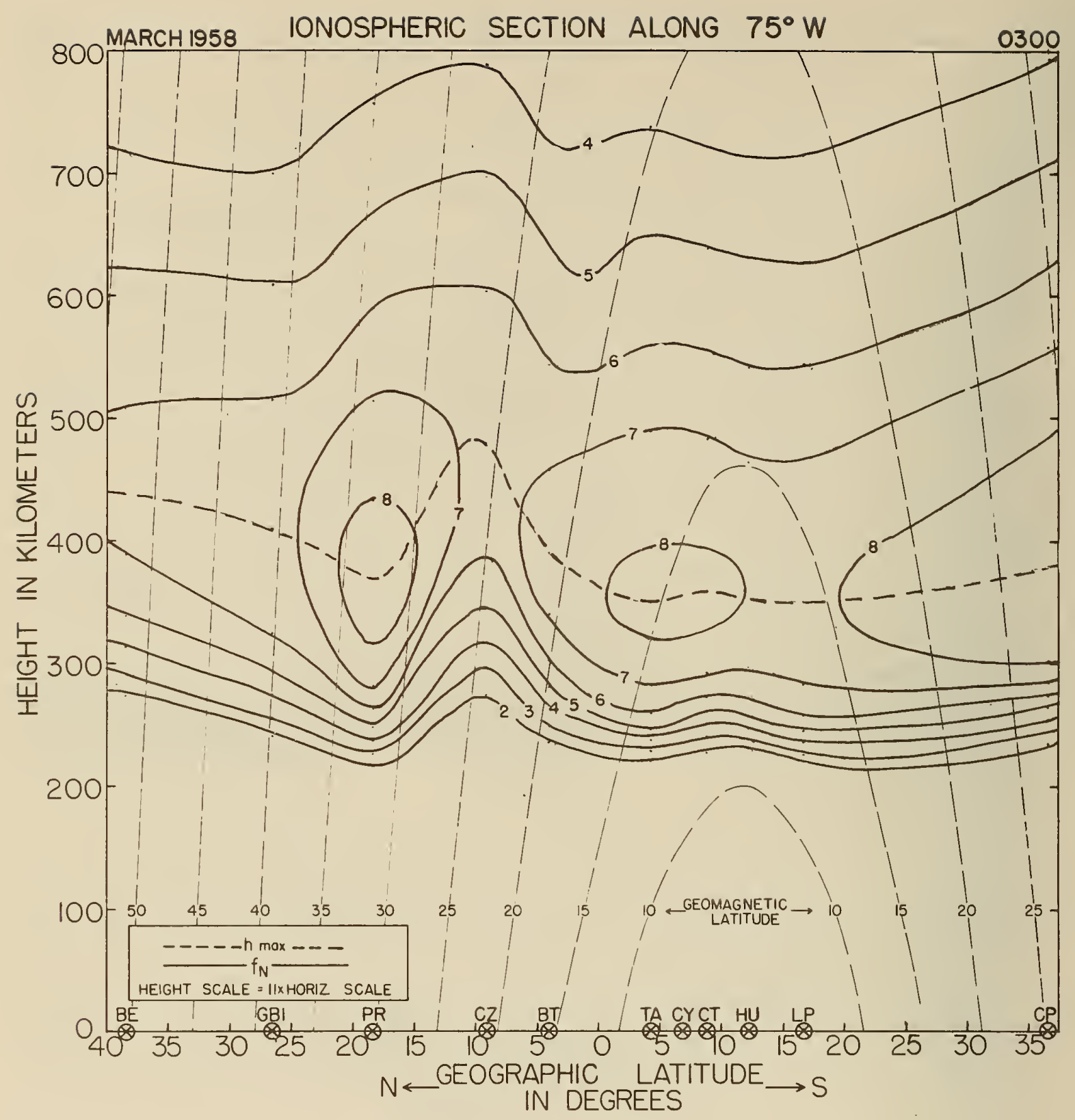




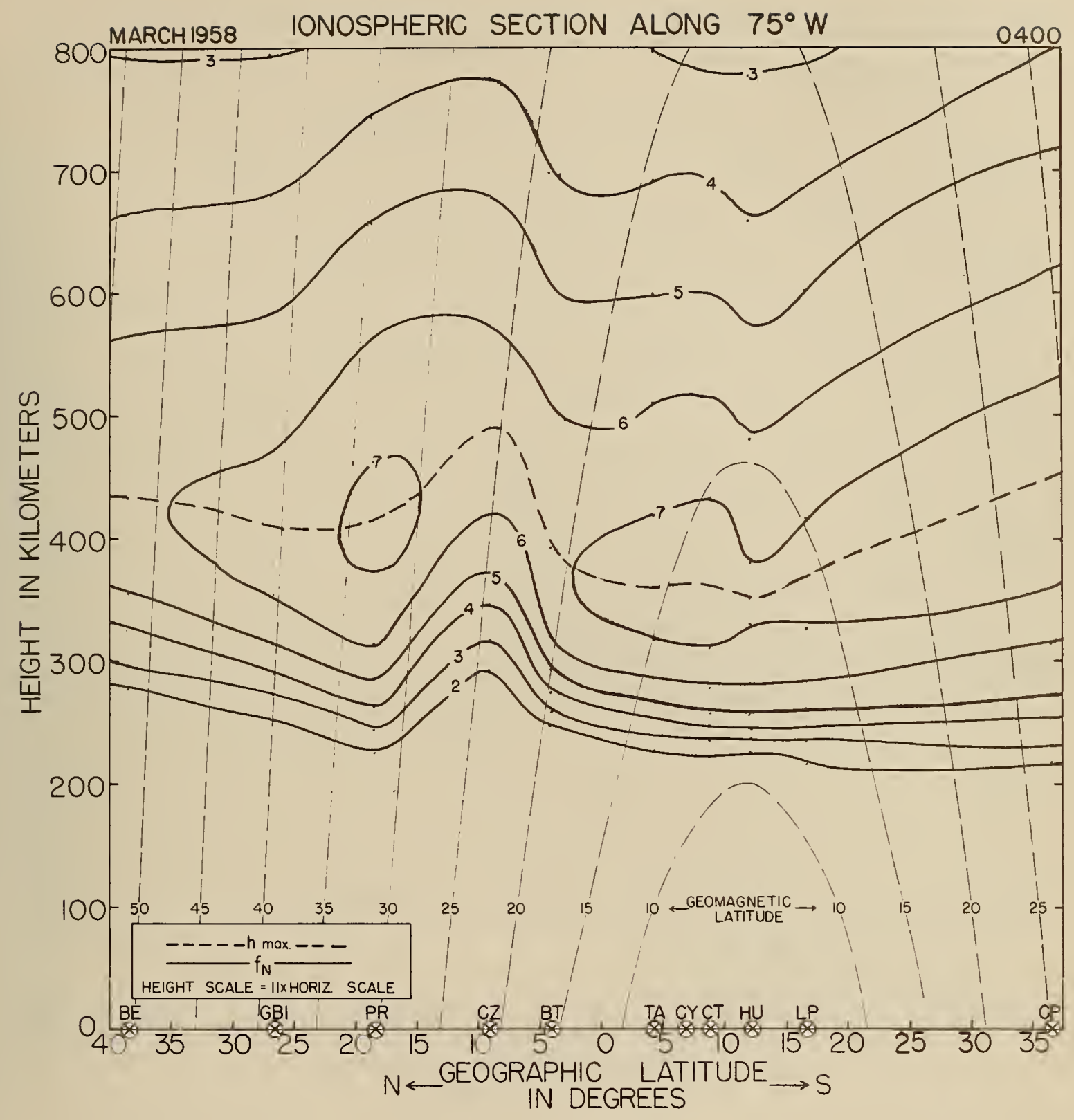




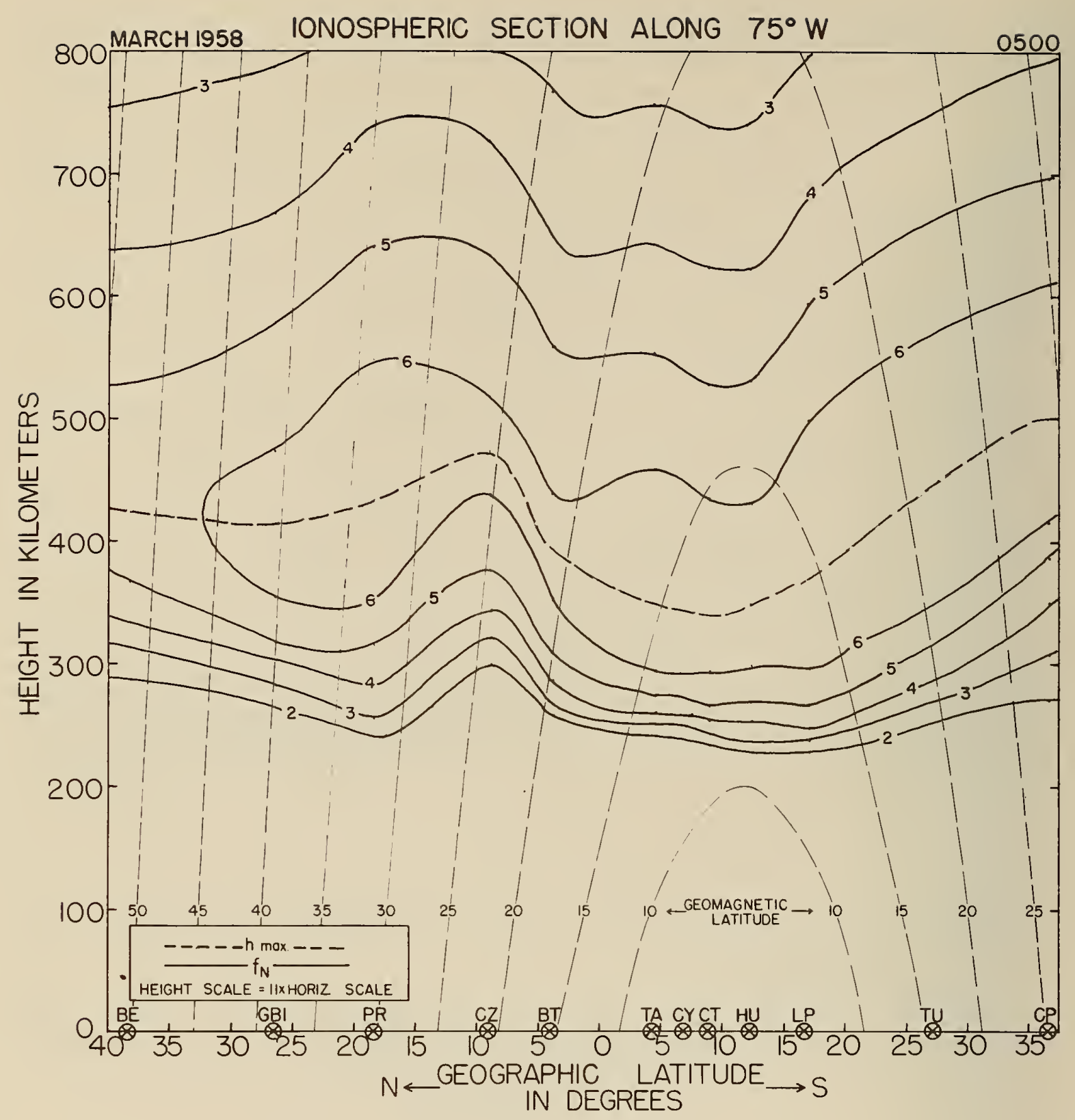




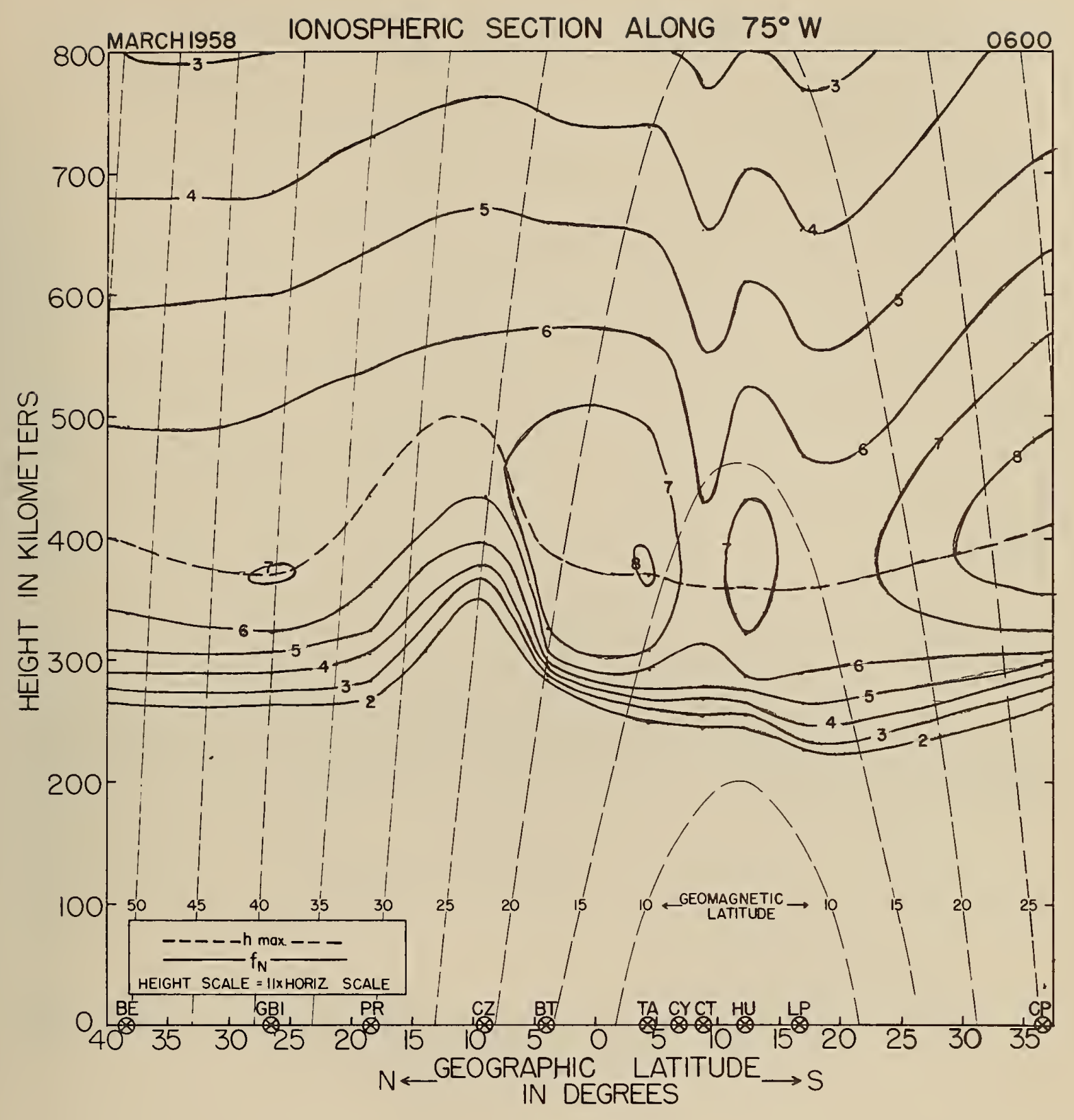




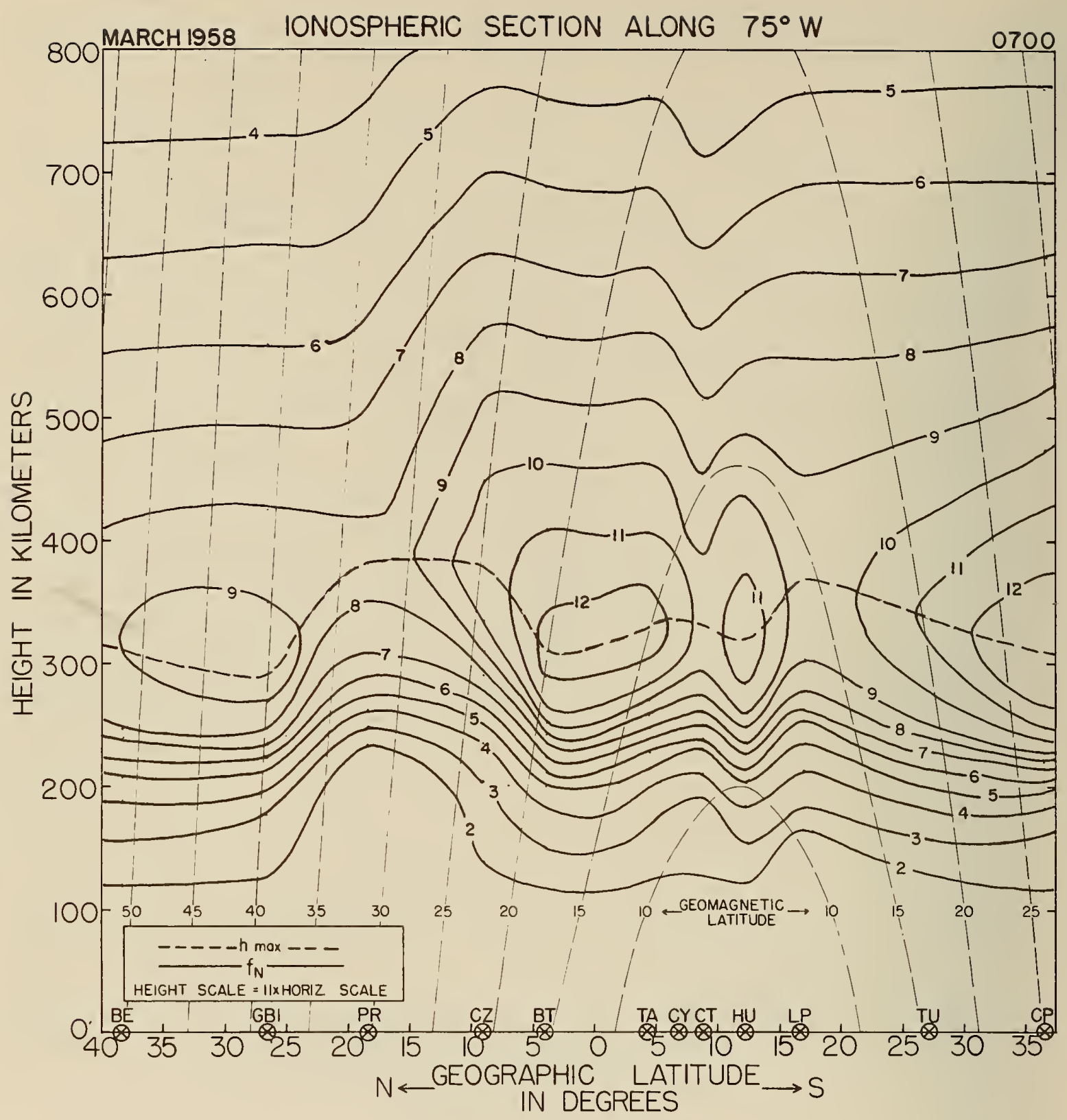




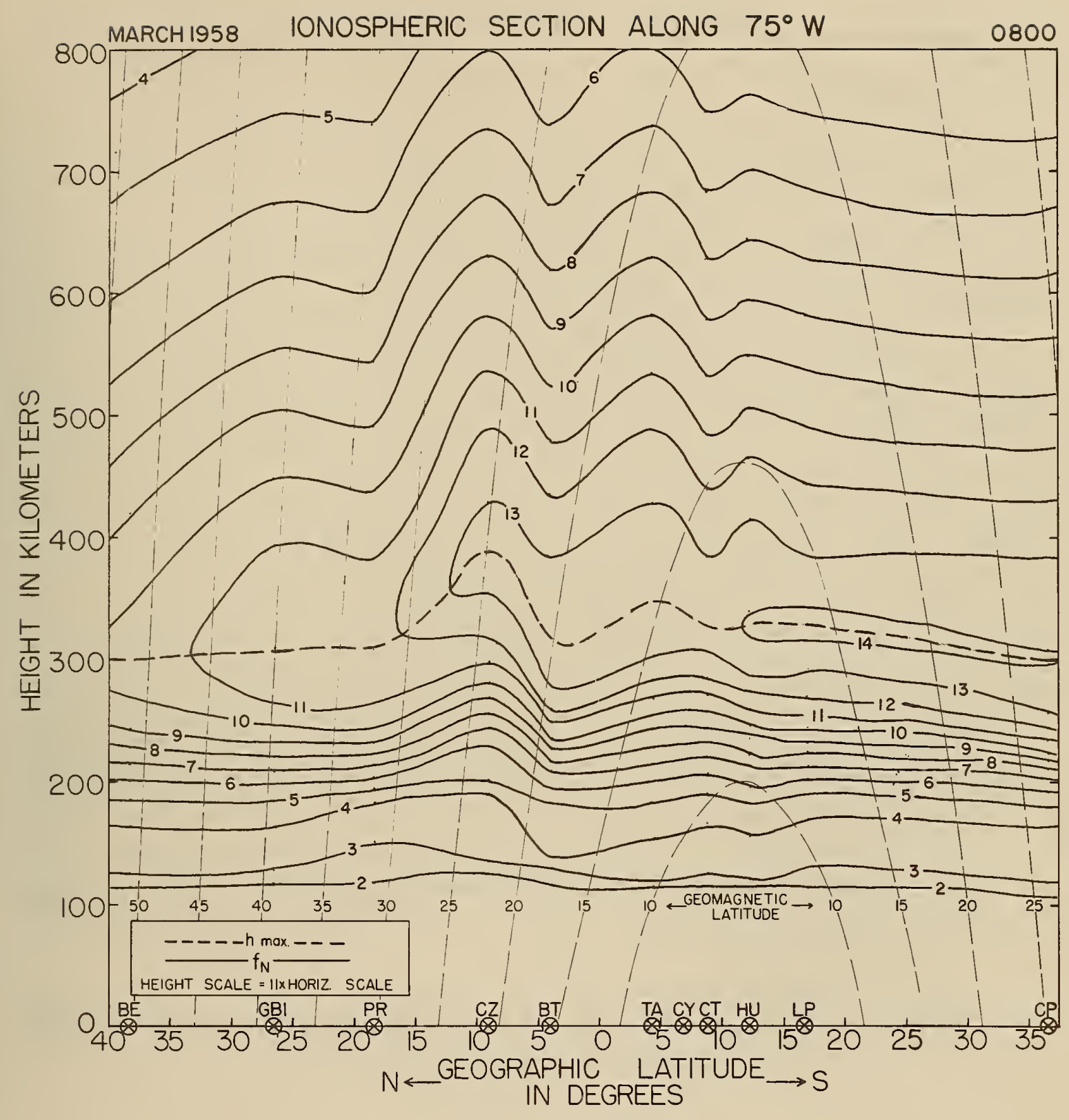




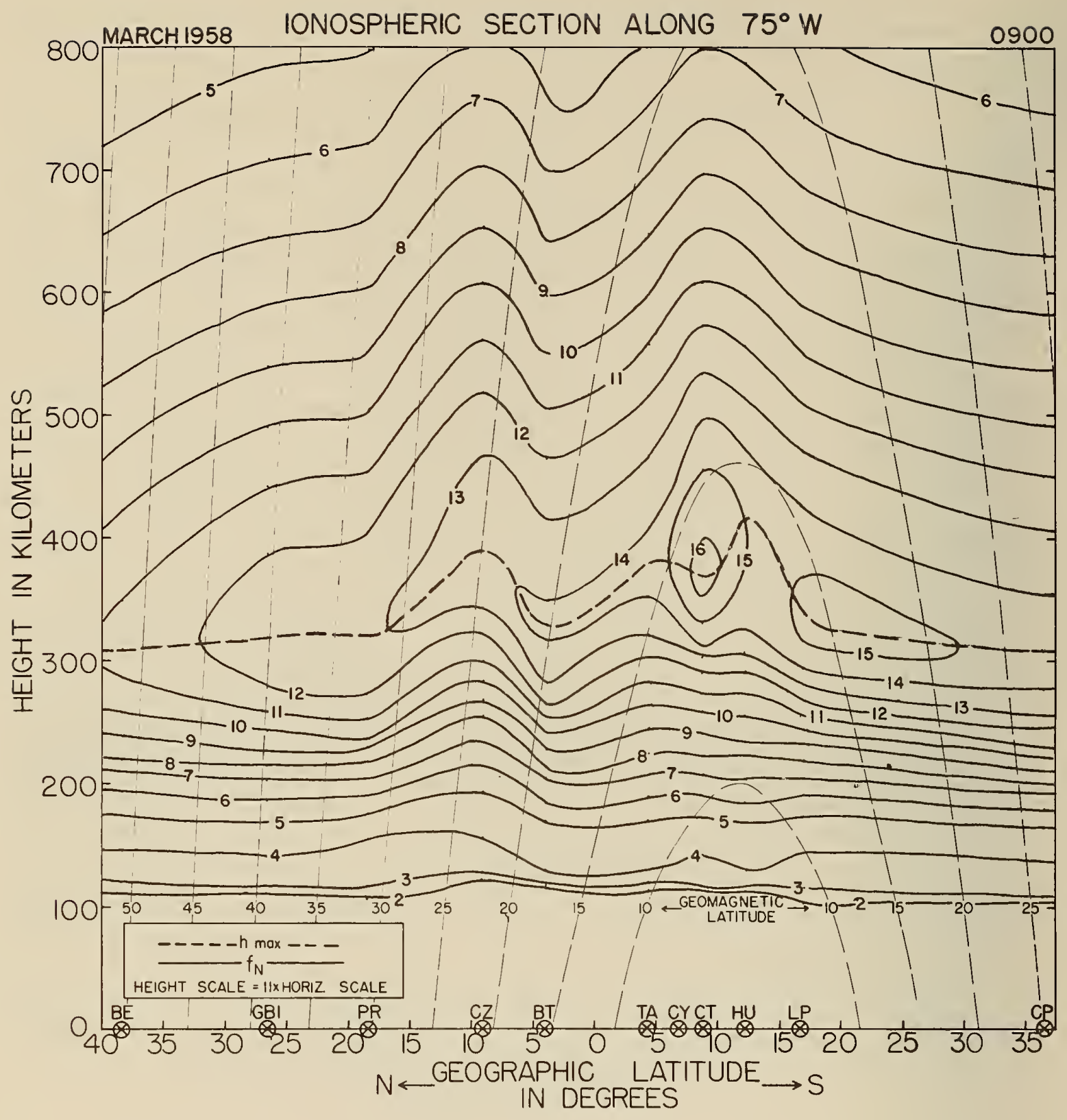




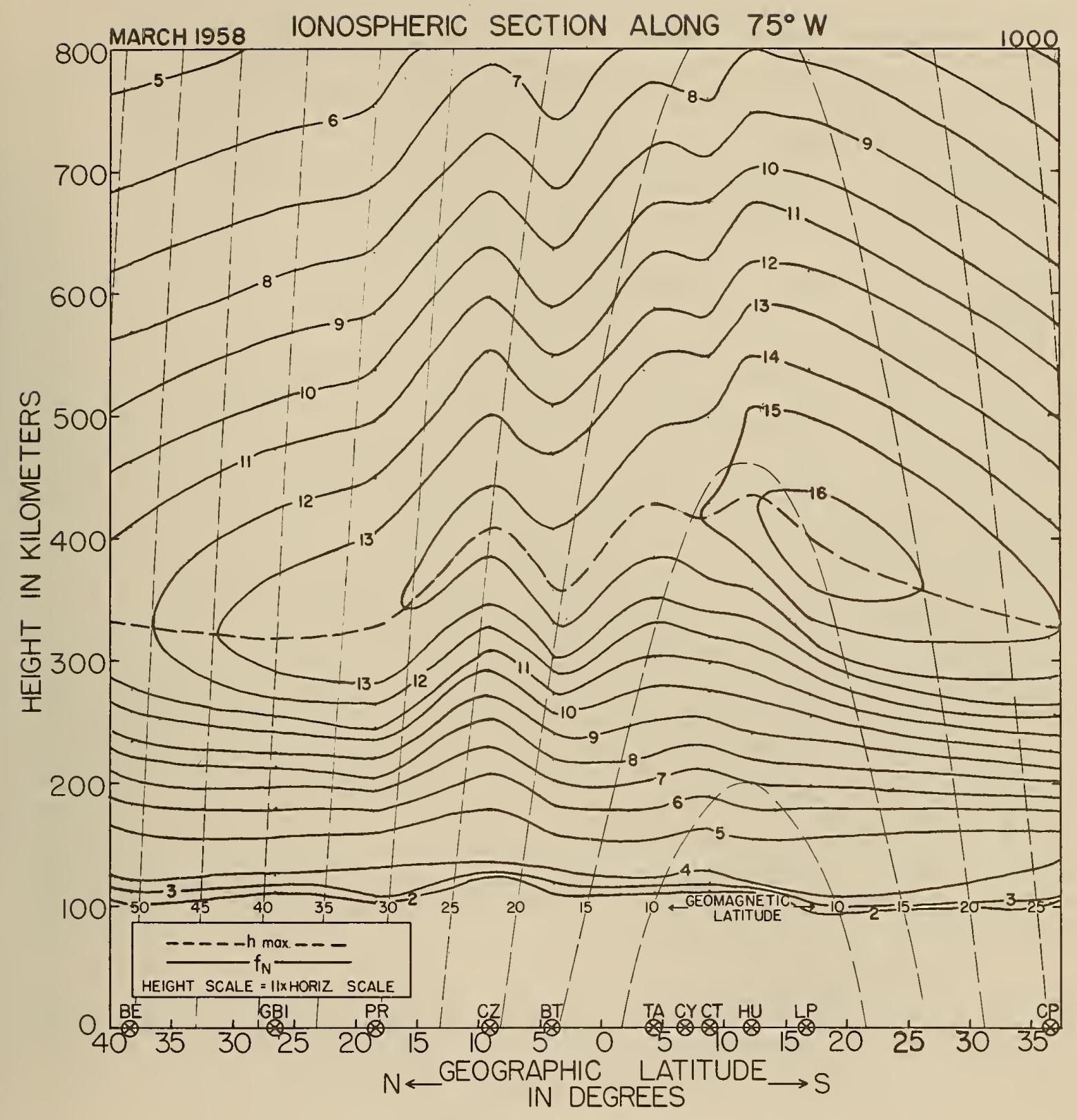




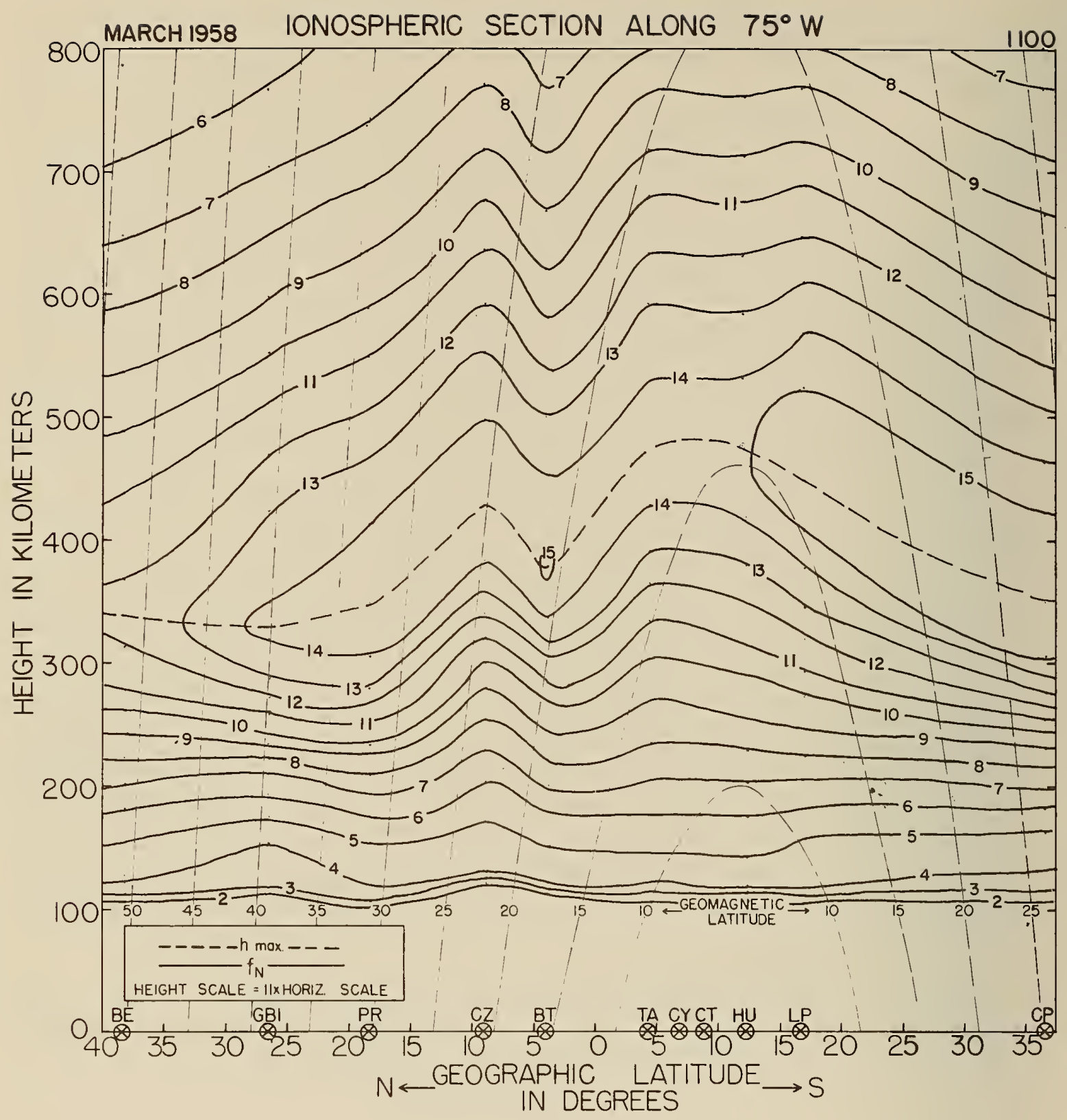




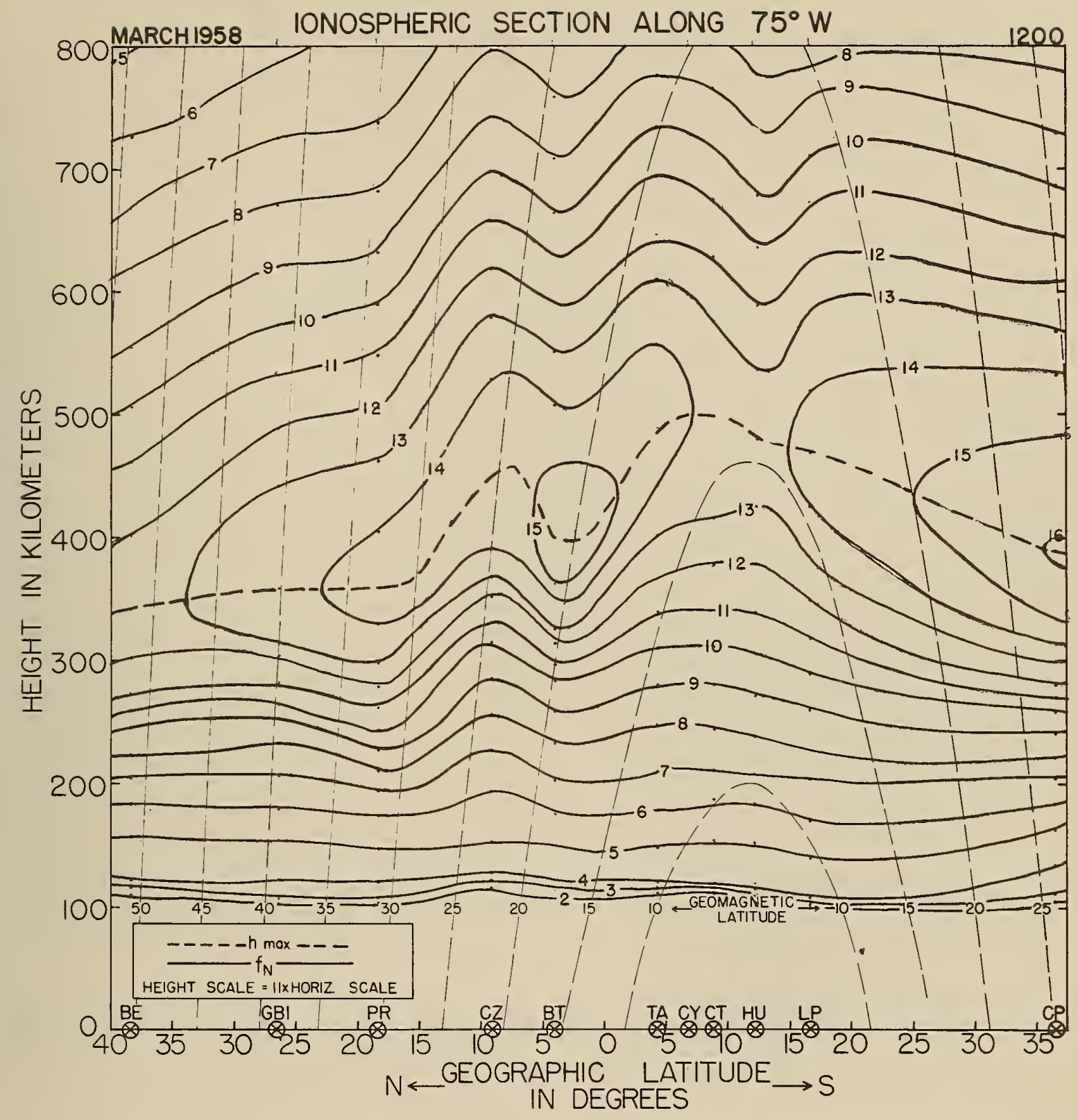




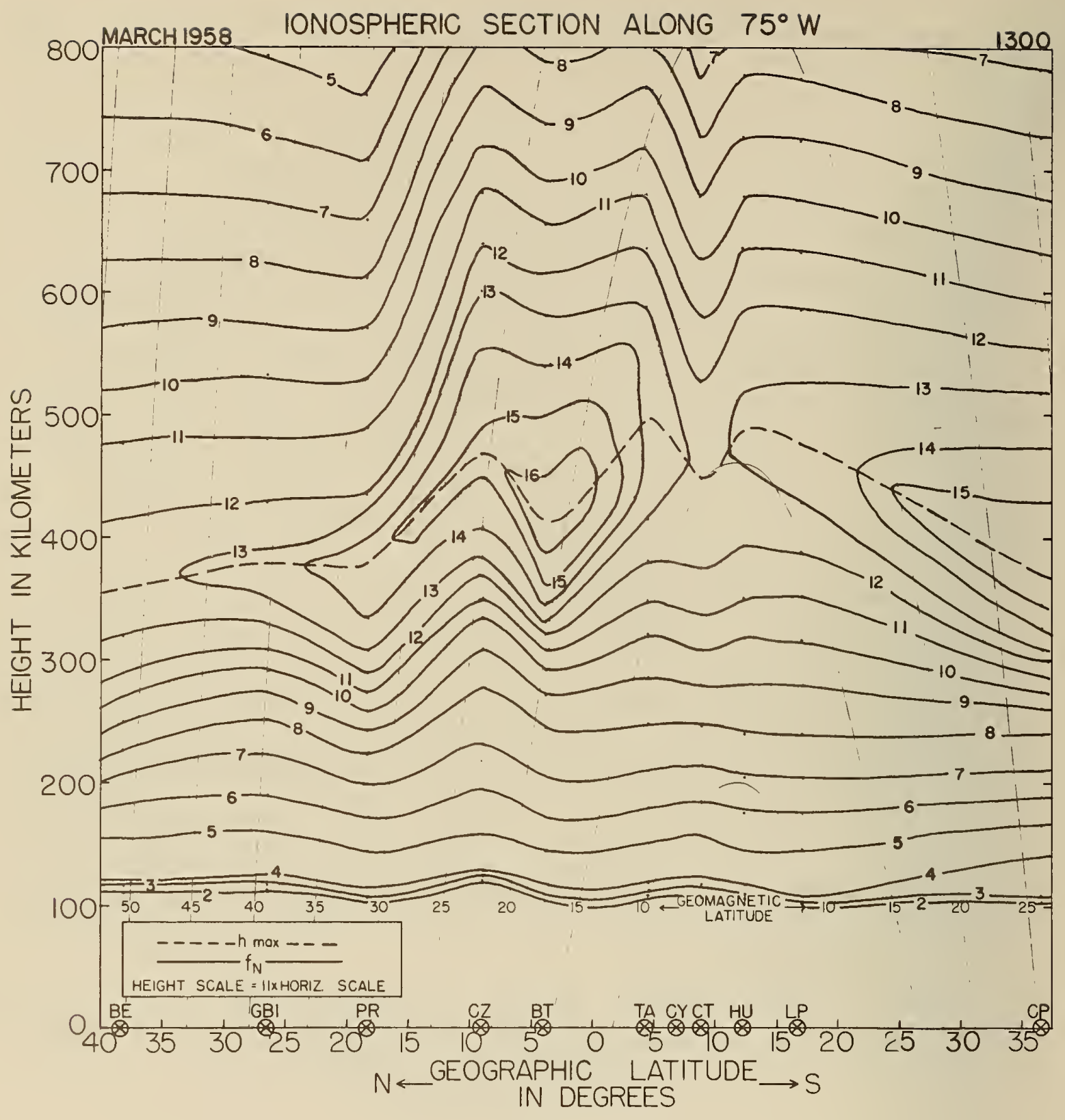




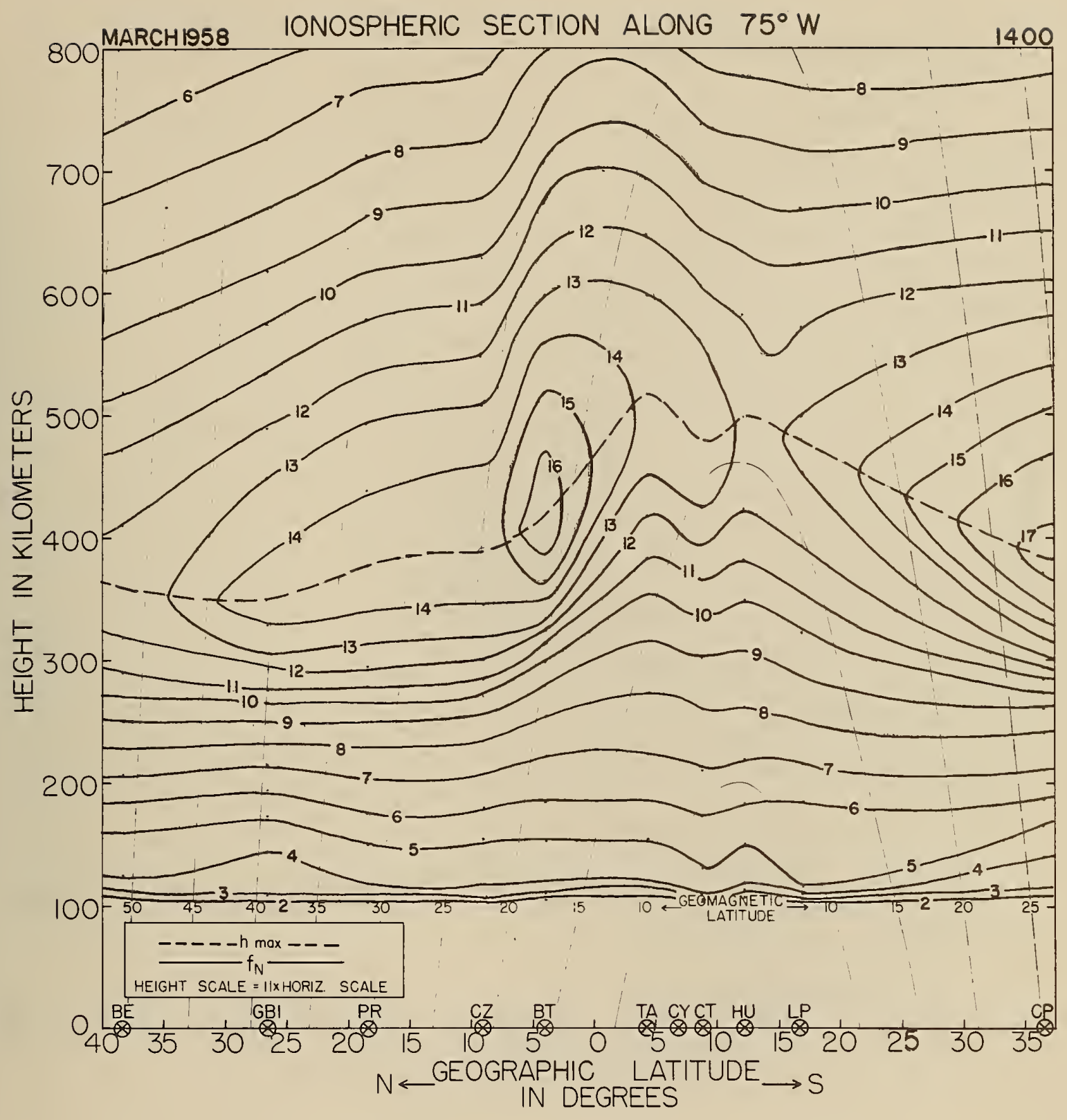




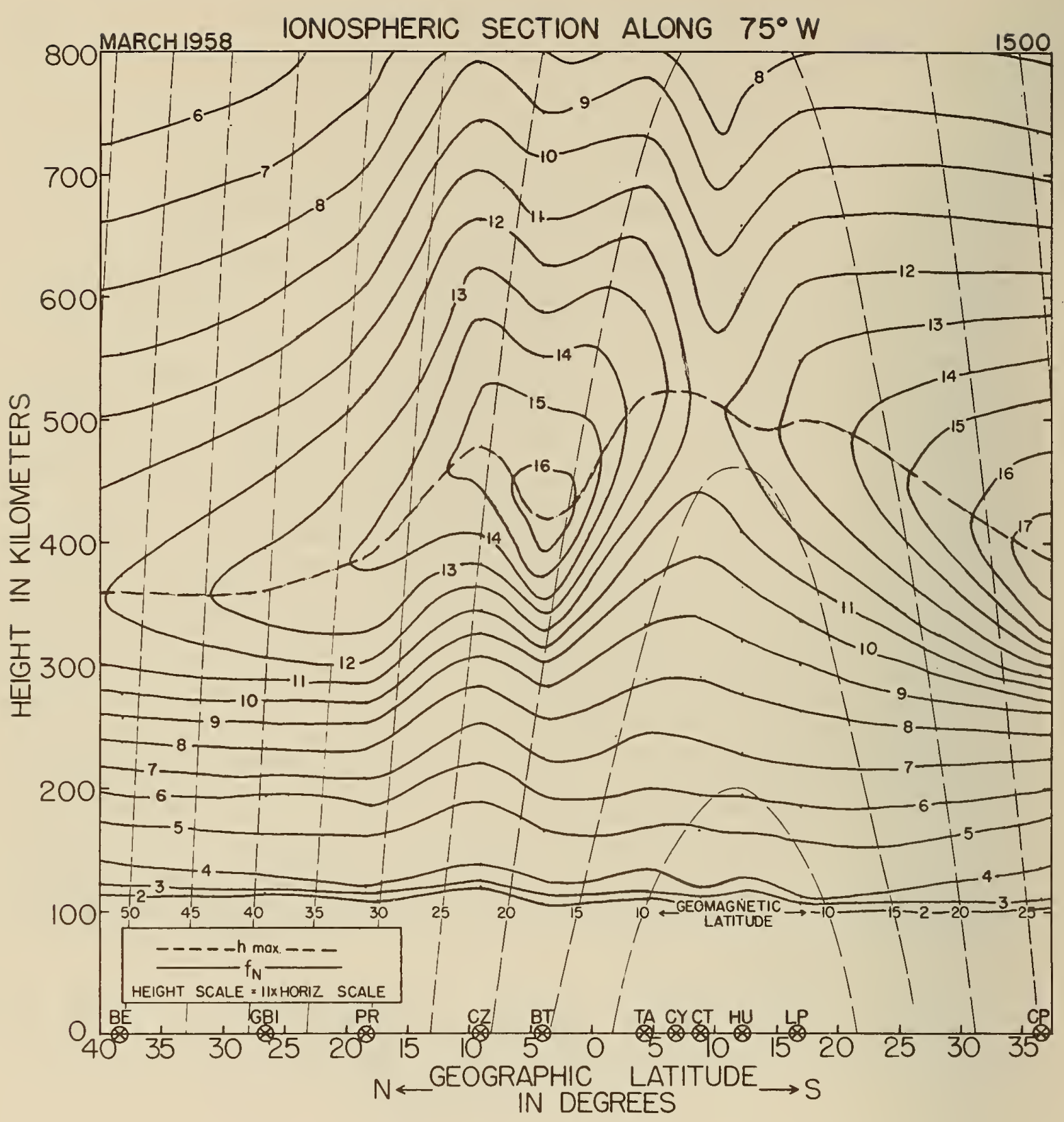




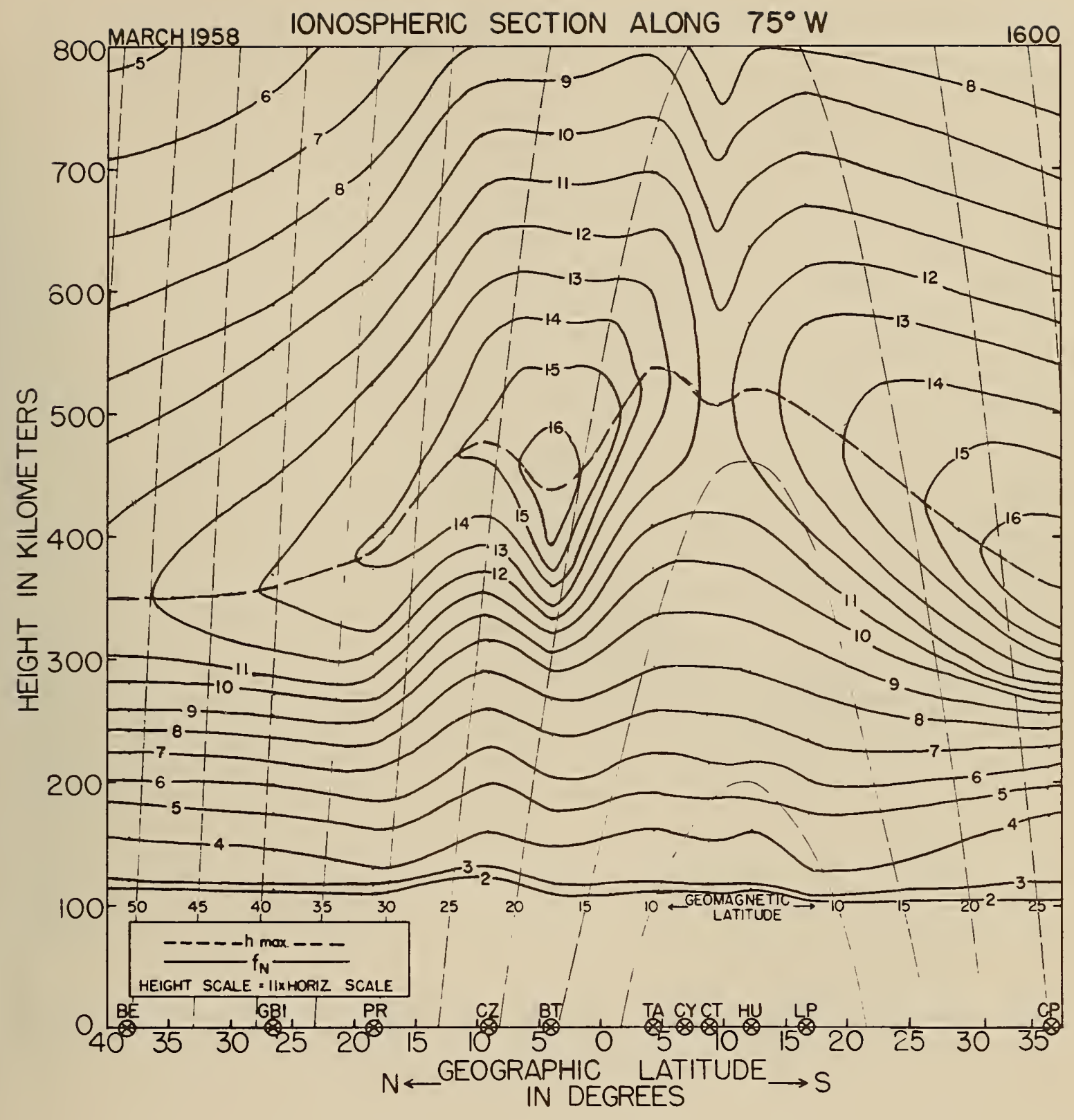




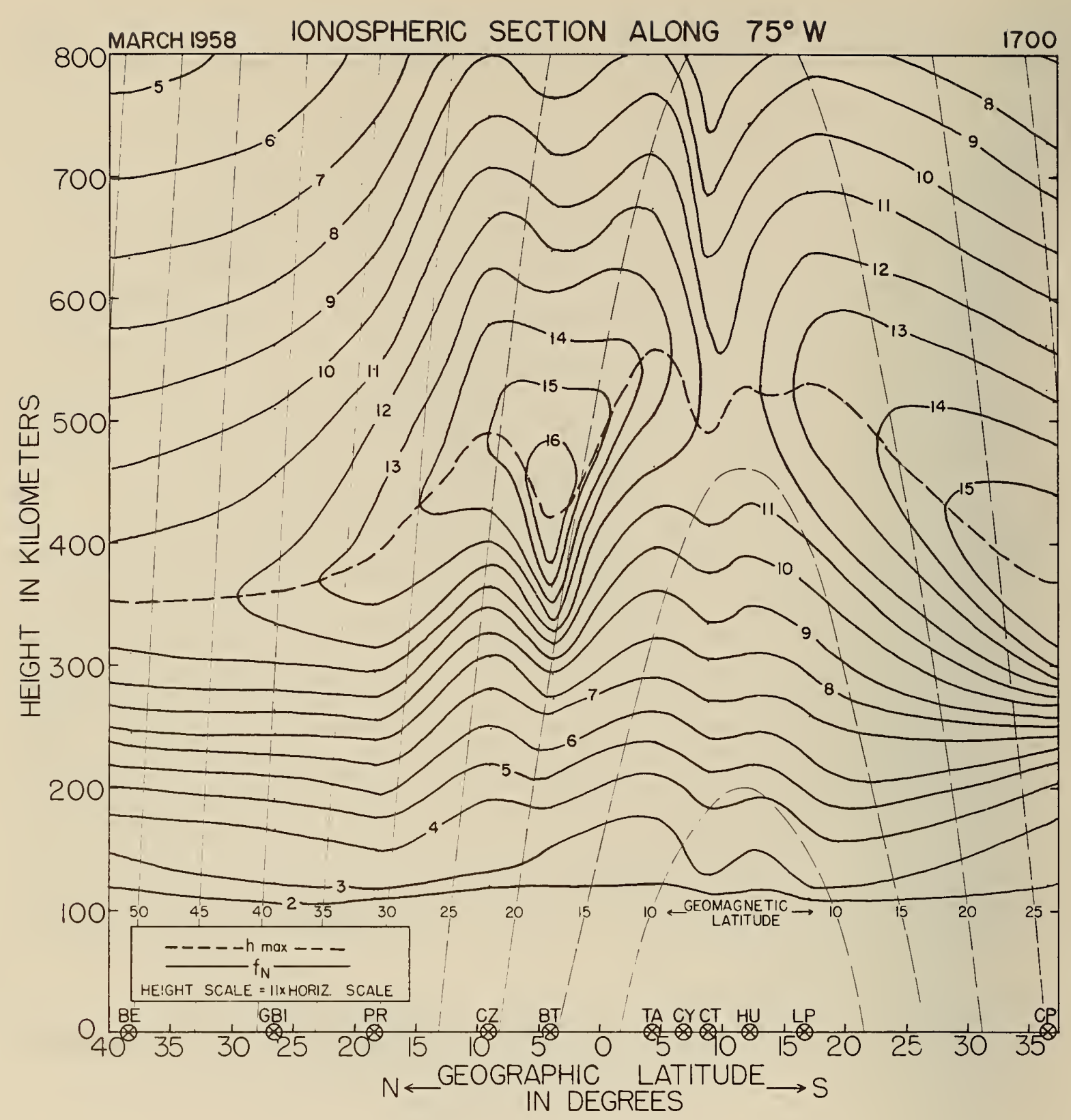




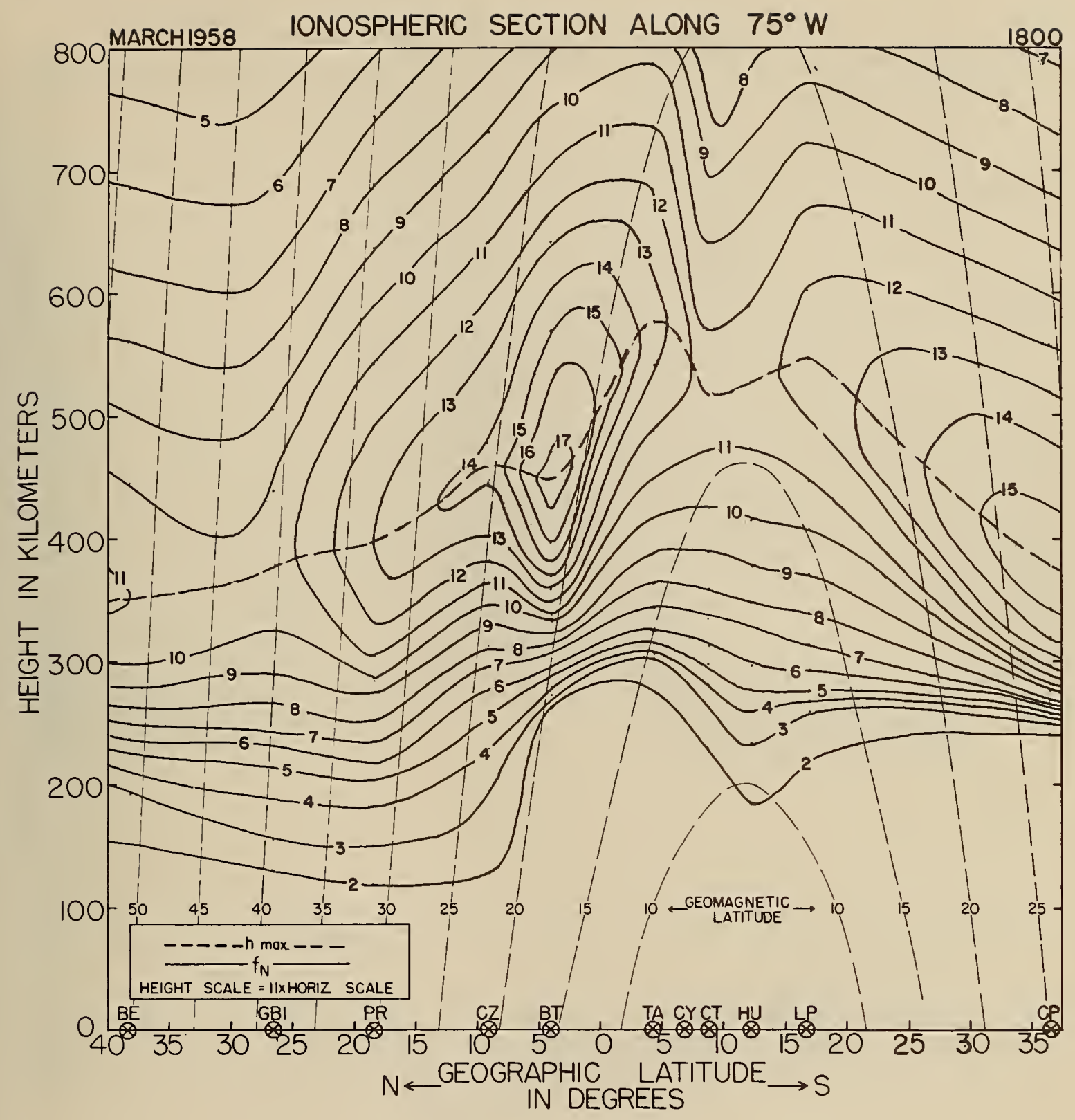




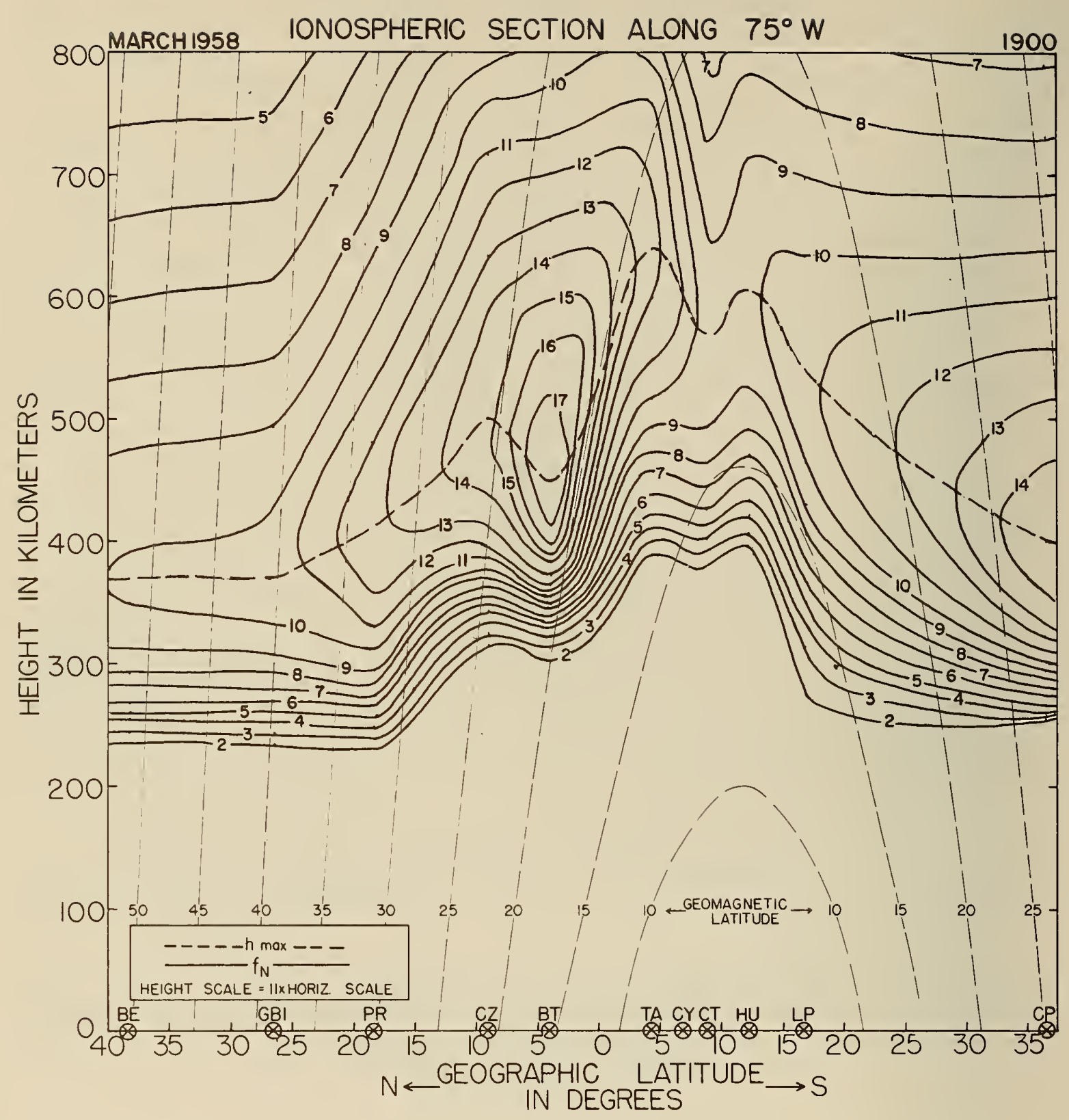




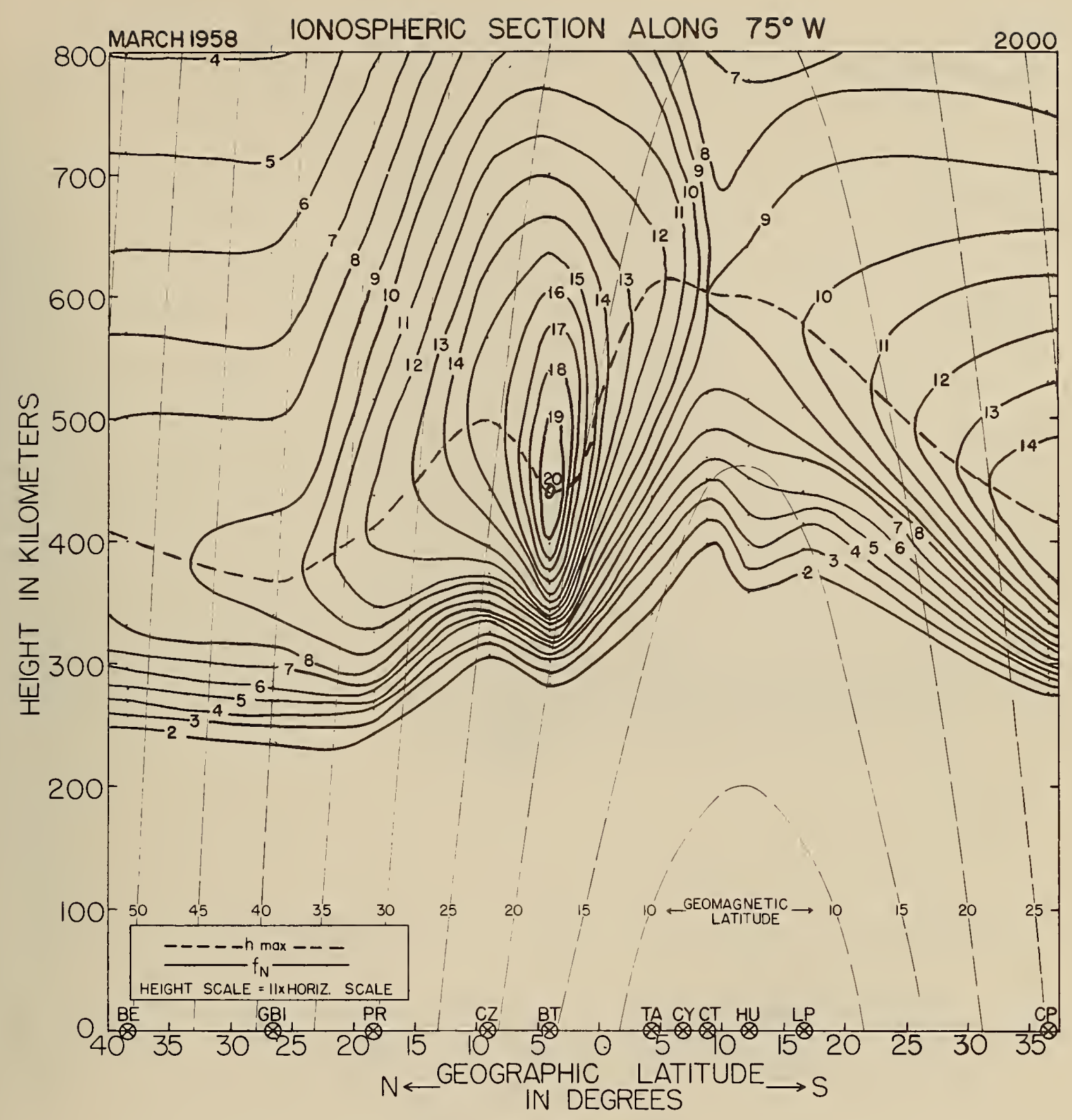




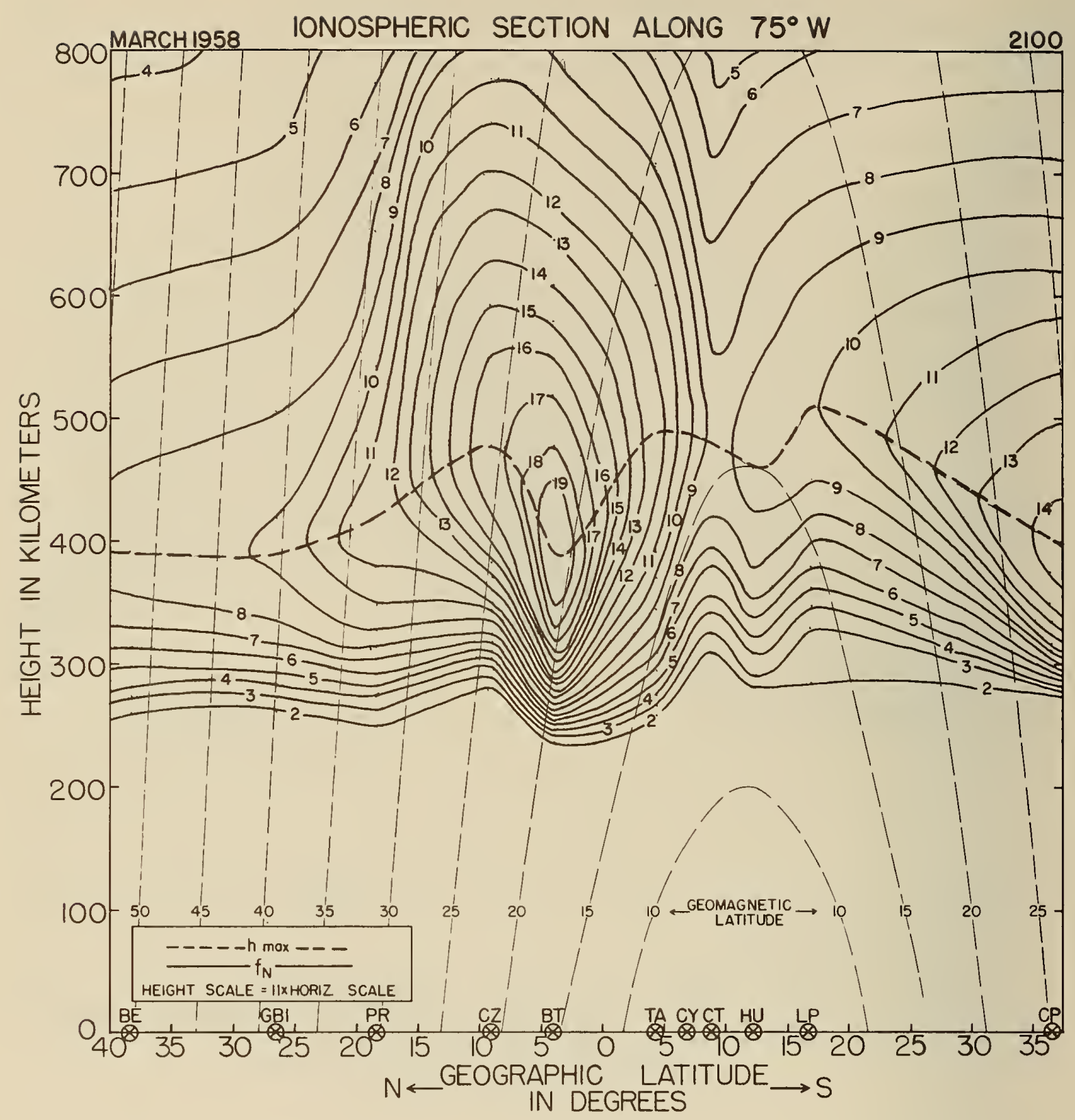




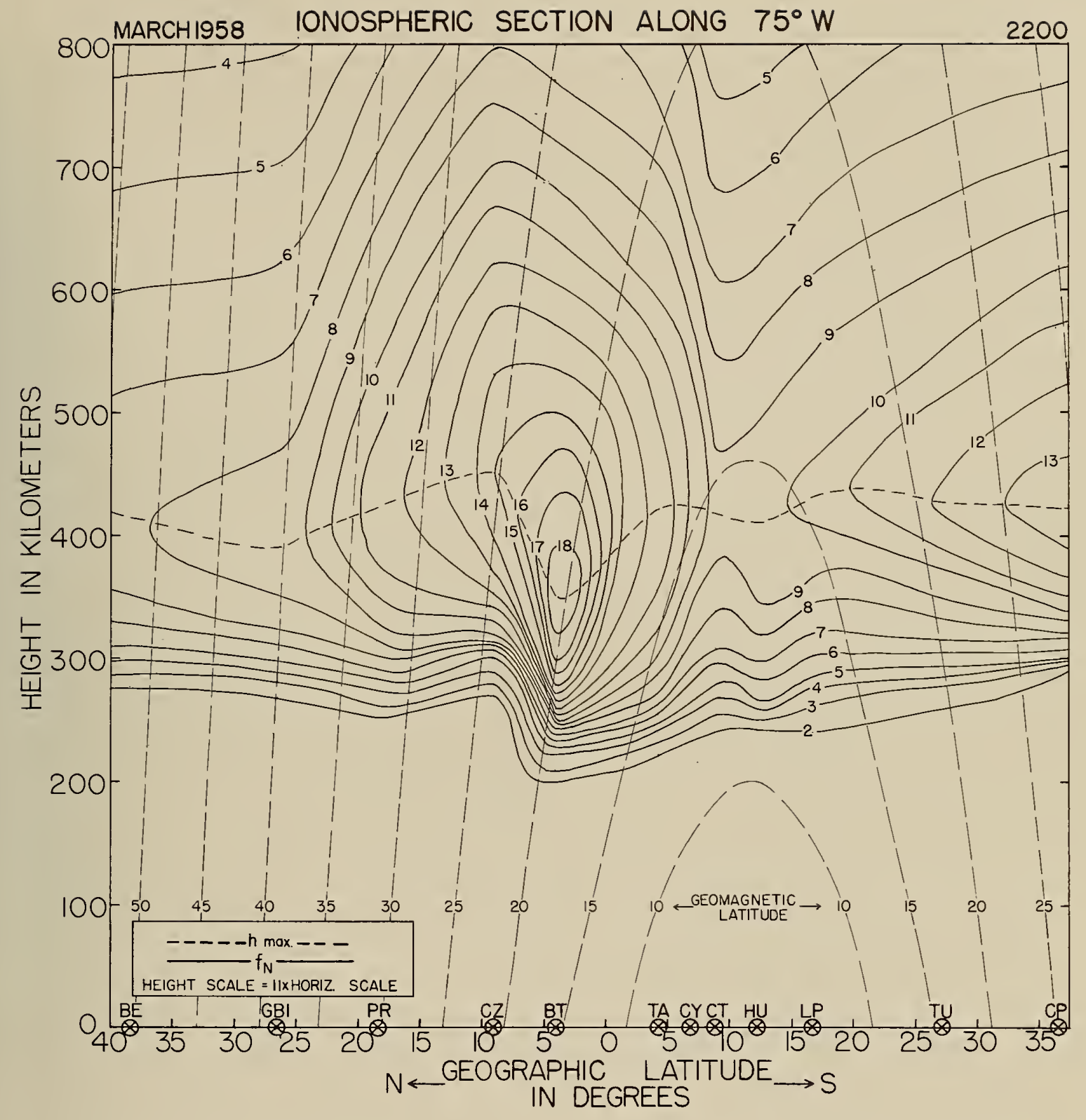




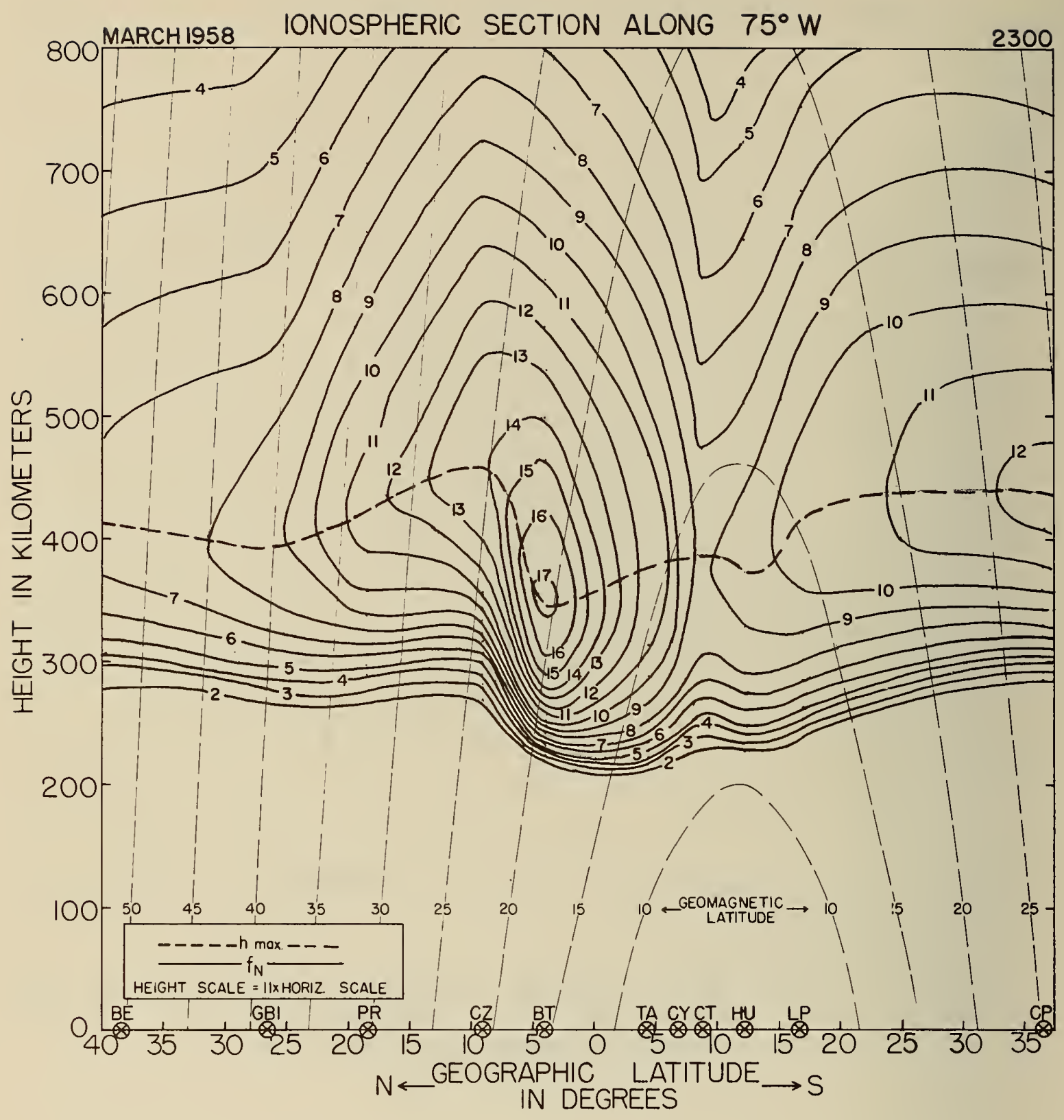


I. S. UH.P IITUHAN OF COMMEHCT

Luther H. Hodges, Secretary

NATIONAL PUUREAL OF STANDAFIDS

A. V. Astin, Director

\section{THE NATIONAL BUREAU OF STANDARDS}

The scope of activities of the National Bureau of Standards at its major laboratories in 1 ashington, 1).C., and Boulder, Colorado, is suggested in the following listing of the divisions and sectionsengaged in teclinical work. In general, each section carries out specialized research, development, aud engineering in the field indicated by its title. A brief description of the activities, and of the resultant publications, appears on the inside of the iront cover.

\section{ASIILVTON, D.C.}

Electricity. Resistance and Reactance. Electrochemistry. Electrical Instruments. Magnetic Measurements. 1)ielectrics. High Voltage.

Metrology. Photometry and Colorimetry. Refractometry. Photogtaphic Research. Length. Engineering Metrology. liass and Scale. Volumetry and Densimetry.

Beat. Temperature Physics. Heat lieasurements. Cryogenic Pliysics. Equation of State. Statistical Physics. Radiation Physics. X-ray. Radioactivity. Radiation Theory. High Energy Radiation. Radiological Equipment. $\checkmark$ ucleonic Instrumentation. Neutron Physics.

Analytical and Inorganic Chemistry. Pure Substances. Spectrochemistry. Solution Cliemistry. Standard Reference laterials. Applied Analytical Kesearch.

llechanics. Sound. Pressure and Vacuum. Fluid Mechanics. Engineering Mlechanics. Rheology. Combustion Controls.

Organic and Fibrous Materials. Rubber. Textiles. Paper. Leather. Testing and Specifications. Polymer Struccure. Plastics. Dental Research.

Vetallurgy. Thermal Vletallurgy. Chemical Metallurgy. Mechanical Metallurgy. Corrosion. Metal Physics. Ellectrolysis and Vetal Deposition.

Vineral Products. Engineering Ceramics. Glass. Refractories. Enameled Vetals. Crystal Growth. Physical Properties. Constitution and Microstructure.

Building Research. Structural Engineering. Fire Hesearch. Wechanical Systems. Organic Building Materials. Codes and Safety Standards. Heat Transfer. Inorganic Building Materials.

Applied Mathematics. Numerical Analysis. Computation. Statistical Eingineering. Mathematical Physics. Operations Research.

Data Processing Systems. Components and Techniques. Computer Technology. Measurements Automation. Engineering Applications. Systems Analysis.

Atomic Physics. Spectroscopy. Infrared Spectroscopy. Solid State Physics. Flectron Physics. Atomic Physics. Instrumentation. Engineering Electronics. Electron Devices. Electronic Instrumentation. Mechanical Instruments. Basic Instrumentation.

Physical Chemistry. Thermochemistry. Surface Chemistry. Organic Chemistry. Mlolecular Spectroscopy. Molecular Kinetics. Mass Spectrometry.

Ofrice of Weights and Measures.

\section{BOULDER, COLO.}

Cryogenic Engineering. Cryogenic Equipment. Cryogenic Processes. Properties of Materials. Cryogeric Technical Services.

Ionosphere Research and Propagation. Low Frequency and Very Low Frequency Research. Ionosphere Research. Prediction Services. Sun-Earth Relationships. Field Engineering. Radio Warning Services. Vertical Soundings Research.

Radio Propagation Engineering. Data Reduction Instrumentation. Radio Noise. Tropospheric Mleasurements. Tropospheric Analysis. Propagation-Terrain Effects. Radio-M!eteorology. Lower Atmosphere Physics.

Radio Standards. High Frequency Electrical Standards. Radio Broadcast Service. Radio and Microwave Materials. Atomic Frequency and Time Interval Standards. Electronic Calibration Center. Millimeter-氐ave Research. llicrowave Circuit Standards.

Radio Systems. Applied Electromagnetic Theory. High Frequency and Very High Frequency Research. Modulation Research. Antenna Research. Navigation Systems.

Upper Atmosphere and Space Physics. Upper Atmosphere and Plasma Physics. Ionosphere and Exosphere Scatter. Airglow and Aurora. Ionospheric Radio Astronomy. 


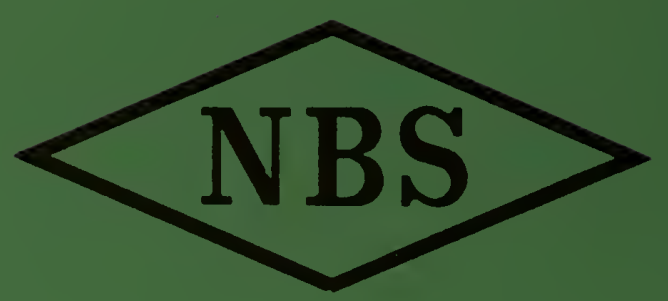

